\title{
Valuing Education
}

\section{The role of soft power in Chinese engagement with Tonga}

\author{
By \\ Regan Priestley Gibbons
}

A thesis submitted to the Victoria University of Wellington in fulfilment of the requirements for the degree of Master of Arts in Political Science 


\begin{abstract}
The bilateral relationship between China and Tonga has existed for almost fifteen years, expanding from an initially limited scope to encompass trade, education, tourism, culture and defence. While China has rapidly expanded its official relationship with Tonga, this expansion has created tensions within Tongan society generated by fears of Chinese immigrants taking jobs and businesses. These tensions boiled over in 2006, as Tongans rioted in the capital Nuku'alofa against Chinese shopkeepers over perceived unfair competition. The aftermath of the Nuku'alofa riots has seen an increasing awareness from China of the need to educate Tongans to its presence in their country, and its goals on the world stage. This new awareness has resulted in China adopting a number of approaches to educate Tongans as part of its expanding engagement. Education has become a central plank of this new-found education campaign, with China introducing several programmes to expose Tongan students to its culture and values, including scholarships for tertiary students to study within China. The purpose of this thesis is to explore the correlation between China's increasing political and economic engagement with Tonga, and the increasing use of education programmes such as scholarships to educate Tongans about China and its culture and values. To accomplish this, the political and economic ties between China and Tonga will be analysed, as will the soft power initiatives that China has undertaken. These will then be analysed to test whether or not the increase in soft power initiatives is due to the expansion of political and economic ties between the two countries. This will allow the use of soft power by China in Tonga to be compared to the trends evident in other South Pacific states, to determine whether Tonga is a unique case or whether China is undertaking these policies across the region.
\end{abstract}




\section{Acknowledgements}

Firstly, I must thank my supervisor; Dr. Marc Lanteigne, who provided me with valuable insight and assistance, during times when it seemed like I had hit a brick wall in trying to conduct research. His knowledge, experience, and contacts in the region were invaluable to me. This thesis would not have been possible if it were not for the teaching of Dr. Anne-Marie Brady, who introduced me to the diverse and interesting subject of Chinese politics in the South Pacific. It is the enthusiasm that she expressed and her encouragement of me to pursue what to me was a relatively unknown subject area that has led me to where I am now. I must also thank my brother Brad, who put up with my constant questions and requests for advice throughout this endeavour. My parents have been a great source of encouragement and reassurance throughout my time writing this thesis, offering words of advice and providing a sounding board when I needed to talk. I also owe a debt of gratitude to Dr. John Barclay, who helped me through an extremely tough period of my life, which threatened to derail my entire thesis. Finally, I must thank all the librarians, advisors, coordinators and other university staff who helped me in some way during my time writing this thesis. While your contribution may have been small, it was an important one. 


\section{Contents}

\section{Table of Contents}

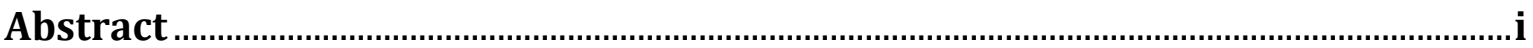

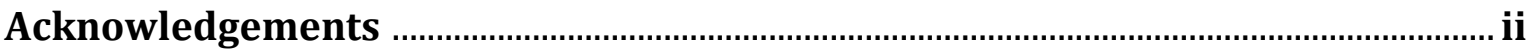

Table of Contents.............................................................................................................

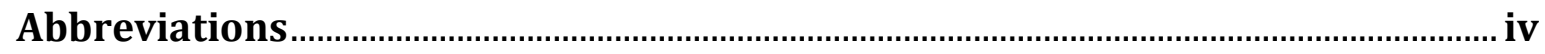

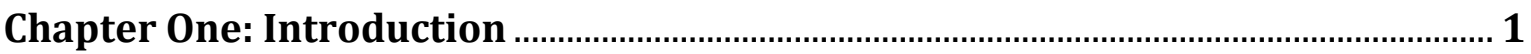

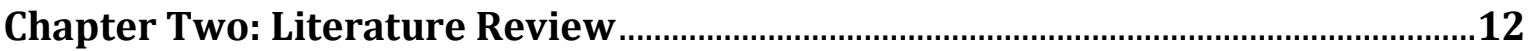

Chapter Three: China-Tonga bilateral relationship ....................................................46

Chapter Four: Chinese soft power in Tonga ................................................................... 53

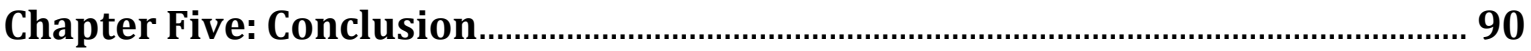

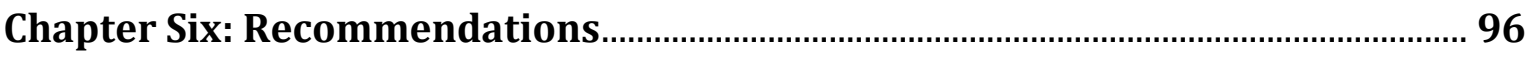

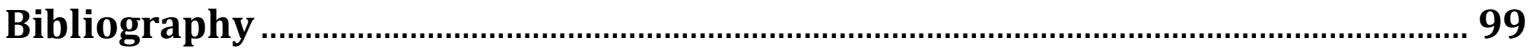




\section{Abbreviations}

ANZ - Australia New Zealand Bank

BRICS - Brazil, Russia, India, China, South Africa

CBD - Central Business District

CMGC - China Metallurgical Group Corporation

CCP - Chinese Communist Party

CSC - China Scholarship Council

EEZ - Exclusive Economic Zone

EU - European Union

FFA - Forum Fisheries Agency

GDP - Gross Domestic Product

GFC - Global Financial Crisis

IMF - International Monetary Fund

MOU - Memorandum of Understanding

NGO - Non-Government Organisation

OC - Overseas Chinese

OPEC - Organisation of Petroleum Exporting Countries

PIF - Pacific Islands Forum

PLA - People's Liberation Army

PRC - People's Republic of China

ROC - Republic of China

UN - United Nations

US - United States of America

WTO - World Trade Organisation 



\section{Chapter One: Introduction}

Soft power has become an important tool to gain and improve the support of other states and their peoples. It has become an attractive alternative to hard power because it does not require the use of coercion or threats, which makes states more attractive. The concept has become an attractive tool in China, following its response to the Asian Financial Crisis of the 1990's, when it provided aid and assistance to Asian economies, such as Thailand and Indonesia. It has also been adopted to gain favour in regions of the world such as Africa, hitherto ignored by the US. China has become an active player in the South Pacific, gradually overtaking other players, such as the United States, in influence held within the region. This rise of China in the South Pacific has been associated with a rise in problems associated with Chinese citizens in the region, such as unregulated immigration, criminal activity by Chinese criminal gangs, and a growing unpopularity of Chinese business practices in the region. To this end, China has turned to education, a soft power tool, to improve its image among the peoples of the South Pacific. The academic research is still in its infancy, with the literature on the subject very limited. This has made China's use of soft power a relatively unknown area. This makes the need to better understand it more important, especially in areas where it is a new player. It is for this reason that China's use of soft power in Tonga must be analysed. It is being used by China in the form of educational programmes, such as scholarships to study at universities in China. The role that it is playing in China's relationship with the South Pacific is a relatively new concept in the field of South Pacific politics. Because of this, it remains relatively under-researched by experts. To contribute to this academic debate, this thesis will test the hypothesis that China is using scholarships to enhance its soft power in the South Pacific, as part of its quest to for greater political and economic engagement. This phenomenon can be more effectively analysed by focusing on a single country as a case study. The role of Chinese scholarships in creating and enhancing soft power in Tonga will be analysed, as part of a wider examination of 
Chinese soft power in the region. The importance of this hypothesis to the academic debate lies in the unique characteristics of China's implementation of soft power and the lack of scholarship on the subject, the latter being the most important. This has created large gaps in the understanding of the concept. The nature of China's relationship with Tonga, especially the role that dependence plays in the relationship, has influenced the nature of China's use of soft power. The hypothesis that will be tested in this thesis is important to the academic debate, because it identifies and analyses an aspect of soft power that is not well-known or understood in the academic field, despite having considerable influence over its implementation by China.

Soft power is the use of ideas, culture and institutions to tacitly attract others to follow a state. The concept was first put forward by Joseph S. Nye in his book, Bound to Lead: the Changing Nature of American Power. It seeks to differentiate itself from the more traditional hard power by attracting others through the use of cooptive power rather than coercive power. The concept rests on three basic tenets; culture, political values, and institutions. These are important because they allow states to shape the preferences held by other states, which enables them to attract those states towards their side. Nye argues that where a state's culture and values are universal in nature, and its institutions able to shape international rules, it can effectively shape the preferences of other states. ${ }^{1}$ The ability to shape the preferences of other states is important to international relations, because it gives states power that is perceived to be less risky than other forms of power. The commanding role of the US as a cultural icon across the globe highlights the role that soft power plays in the international system. Soft power is transmitted to other states through a number of alternative methods to traditional ways of wielding power. One way that a state's culture is transported to other societies is through the use of educational exchanges. ${ }^{2}$ Another example is the use of institutions within the international system, such as the UN. Western powers used their position within the UN to push for the protection of democracy and human rights in the UN charter. ${ }^{3}$ The two examples highlighted show

\footnotetext{
${ }^{1}$ Nye, Jr., Joseph S, Soft Power: The Means to Success in World Politics (New York: Public Affairs, 2004), p.11

${ }^{2}$ Nye, Jr., Joseph S, The Future of Power (New York: Public Affairs, 2011), p.85

${ }^{3}$ Nye, Soft Power, p.10
} 
the way that soft power works, and how it has differentiated itself from the traditional forms of power. Critics, such as neo-realist scholar Stephen Walt, have argued that the key aspects of it, such as attraction and imitation, are not forms of power. ${ }^{4}$ They also argue that popularity measured by opinion polls is temporary, and because of that cannot be taken seriously. ${ }^{5}$ These criticisms are aimed at the lack of complete control that states hold over soft power. Nye has argued that it is not completely within the control of states and often comes from non-state actors, which makes it hard to use, easy to lose and costly to re-establish. ${ }^{6}$ Much of the criticism levelled is based on this statement, because unlike hard power, soft power is influenced by perceptions, values, and other actors. This criticism exposes significant flaws in the theoretical framework, which require better understanding if the concept is to be applied to China's relationship with the South Pacific.

Because soft power's focus is on attraction rather than coercion, this makes knowledge, understanding, and branding crucial to enhancing the amount of soft power that states wield. The role that knowledge and understanding plays has meant that education has become a significant tool. This is because it can be created or enhanced by educating those citizens of the state you are seeking to attract about your culture, values and heritage. Nye emphasised the importance of these values in creating the attraction that is important, and education has proved crucial to informing outsiders about your culture. This is because education is recognised globally as a significant part of life, and is widely attended by children and young adults almost everywhere. Education has been associated with soft power since the term was first coined by Nye, in Bound to Lead. This makes it an important tool to use, because it ensures that a large audience is exposed to the message that states are trying to communicate. Education has become a crucial tool in the soft power arsenals of several states, many of whom wield great amounts.

One state that uses education as part of its arsenal is the US. The US possesses a great deal of power, which it wields across much of the globe. Education has become an integral part of the US's soft power arsenal, influencing the opinions of citizens from countries it traditionally competes with for power. One such example of this is the US's position as an attractive destination to send students for tertiary

\footnotetext{
${ }^{4}$ Nye, Soft Power, p.18

5 Ibid

${ }^{6}$ Nye, The Future of Power, p.83
} 
education. The US's university system has developed a reputation for excellence, which has resulted in the children of influential figures being sent to the US for higher education. ${ }^{7}$ Nye states that students who study in the US often assume leadership roles later in life that enable them to affect policy outcomes favourable to the US. ${ }^{8}$ The case of the US highlights the significance attached to education in the field of soft power.

This concept has led to a theoretical split between those who consider economic power to be a form of soft power and those who consider it a hard power tool. This theoretical split has been led by Joshua Kurlantzick, who argues that China is using its economic power as a form of soft power, to attract developing states and those disaffected with the policies of the US. ${ }^{9}$ China uses its history as a developing state and one that was subjected to colonialism at the hands of Western powers to emphasise its kinship with other developing states, as an alternative to the other established superpowers. Kurlantzick argues that the combination of China's economic model, which refuses to accept the US orthodoxy of leaving it solely to the free market, and its use of diplomacy, has allowed it to develop significant appeal among developing states. ${ }^{10}$ This model has proved attractive largely due to the success China has experienced by using it. The successful combination of private enterprise openness, a large state sector, and stalling of democratic reform has allowed China to expand and improve its economy, and become a superpower that is competing with the US. China has used its economic strength to become influential in providing financial aid to developing states, as part of its diplomatic strategy. This has greatly enhanced China's standing among developing states, who appreciate the provision of assistance without the strings attached that Western powers traditionally require, such as good governance requirements and free market reforms. It is in this respect that Kurlantzick's "Charm Offensive" model splits from the traditional definition of soft power. Nye's definition argues that economic power is not soft power because it coerces rather than attracts. In regards to China, its

\footnotetext{
7 Nye, Joseph S., "Soft Power and Higher Education", 2004, http://net.educause.edu/ir/library/pdf/ffpiu043.pdf (accessed May 26, 2012), p.43

8 Ibid

${ }^{9}$ Kurlantzick, Joshua, "China's Charm Offensive", Commentary, vol. 122, no. 3, 2006, p.37

${ }^{10}$ Kurlantzick, "China's Charm Offensive", p.36
} 
economic model encompasses aspects of both forms of power. As Kurlantzick identifies, China's economic model has created significant levels of attraction among developing states. In contrast to this, China's provision of financial aid to developing states can be identified as hard power, due to the coercive nature of aid distribution. This theoretical split in the relationship between economic power and soft power is important, because it identifies and provides an explanation for the role that economic power is playing in China's foreign policy. However, China is now seeking to expand its soft power into other sectors. This split does however create a need to identify which type of soft power to use for this analysis. For the analysis of China's use of scholarships in the South Pacific as part of its quest for greater soft power, the revision of Nye's framework put forth by Kurlantzick is more appropriate. This is because China's use of aid provision in Tonga has enabled it to adopt the soft power initiatives being analysed. Kurlantzick's revision is better able to take this into account than the original framework put forth by Nye.

The South Pacific provides an effective case study for this analysis, because it presents several unique characteristics that differentiate it from China's other relationships. This makes it an important test case for the academic field, because the nature of China's relationship with Tonga provides important insights into the way it implements soft power initiatives in the region. This relationship is dominated by economic dependence on the part of Tonga, due to its lack of exports, and underdeveloped tourism industry. This weak economy has made Tonga dependent on Chinese aid and loans, which make up a considerable proportion of its GDP. This dependence has influenced the nature of the relationship, which has dictated the way that China uses soft power in the country Economic dependence has made China's relationship with Tonga considerably different from its other relationships in the region, which makes it an important case, in need of greater analysis.

\section{Definitions}

Because the analysis being undertaken in this paper will focus on a number of concepts, terms must be defined before the analysis can proceed. These terms are important to the analysis because they frame the argument, and as such must be 
defined to ensure the argument is focused on addressing the hypothesis. Three terms have been selected that are in need of definition, these are; the South Pacific, culture and values.

The South Pacific is a geographic region south of Indonesia, the Philippines, Taiwan, and Japan, encompassing the regions of Melanesia, Micronesia, and Polynesia. ${ }^{11}$ For the purposes of this analysis, the definition of South Pacific will be drawn from that used by the UN statistics division. This definition states that Oceania consists of the independent states of Australia, New Zealand, Fiji, New Caledonia, Papua New Guinea, Solomon Islands, Vanuatu, Guam, Kiribati, Marshall Islands, Federated States of Micronesia, Nauru, Northern Marianas Islands, Palau, American Samoa, Cook Islands, French Polynesia, Niue, Samoa, Tokelau, Tonga, Tuvalu, and the Wallace and Futuna Islands. ${ }^{12}$ The use of the term South Pacific in this thesis will refer to the countries within these boundaries, south of the equator. This will exclude the states of Kiribati, Marshall Islands, Federated States of Micronesia, Northern Marianas Islands, and Palau, as they are north of the equator.

Culture is a term that has importance across several academic fields. It has been an important part of the fields of anthropology and sociology, but has increasingly become significant to political science. Because of this, the term culture will be defined from the sociological definition. According to the Oxford Dictionary of Sociology, "culture is all that in society which is socially rather than biologically transmitted. Culture is thus a general term for the symbolic and learned aspects of human society".13 The SAGE Dictionary of Sociology also provides an important definition for culture. According to SAGE, "the culture of a society is the totality of its shared beliefs, norms, values, rituals, language, history, knowledge and social character". ${ }^{14}$ Drawing on these two definitions, in this analysis culture will refer to socially transmitted beliefs, norms, language and values within a society. This will guide the analysis of the effect that China's scholarship programmes have had on the

\footnotetext{
11 Everett-Heath, J., 'Concise Dictionary of World Place-Names', 2010, http://www.oxfordreference.com/views/ENTRY.html?subview=Main\&entry=t209.e5461 (accessed 27 August 2012), p.1

12 UN Statistics Division, 'Composition of macro geographical (continental) regions, geographical subregions, and selected economic and other groupings', 2011, http://millenniumindicators.un.org/unsd/methods/m49/m49regin.htm\#oceania (accessed 27 August 2012)

${ }^{13}$ Scott, J., \& G. Marshall, Oxford Dictionary of Sociology (New York: Oxford University Press, 2005), p.133

14 Bruce, S., and S. Yearley, The Sage Dictionary of Sociology (London: Sage Publications, 2006), p.58
} 
understanding of Chinese culture, and its effect on the quest for greater political and economic engagement with Tonga.

Values play an important role in politics, with values influencing almost every action taken by states, such as by influencing decision-making. The term values must be clearly defined to ensure that future analysis is appropriately targeted towards the right area. According to the SAGE Dictionary of Sociology, "they are ethical principles and ideals: statements of what should be, rather than what is". 15 The Oxford Dictionary of Sociology goes further, defining values as, "ideas held by people about ethical behaviour or appropriate behaviour, what is right or wrong, desirable or despicable". ${ }^{16}$ Drawing from these definitions, the term values that is used in the analysis will refer to the ethical principles and values held by individuals and societies about behaviour.

The definitions provided here for the terms South Pacific, culture, and values will be crucial to the analysis that will take place in this paper. This is because they ensure that the analysis focuses on the relevant area, and obtains the correct information.

\section{Chinese culture and values in foreign policy}

As a result of Beijing's foreign policy expansion, culture and values have become an important aspect of the ideas being implemented within the field of Chinese foreign policy. This is part of a wider effort by China to use foreign policy to allay fears that it is seeking to threaten the established world order. China is using foreign policy to counter this idea, through the use of strategies such as the "peaceful rise" theory, which describes China's foreign policy approach as seeking to emphasise its peaceful nature. This approach includes a focus on attraction-based approaches, of which Chinese culture and values have become a significant component. Culture is being used by China in its overseas education institutions to show outsiders a favourable image of China. This is evident in the expansion of Confucius Institutes in tertiary institutions across the world. These institutes are non-profit organisations aligned with the Chinese government, whose aim is to provide teaching about

\footnotetext{
15 Bruce \& Yearley, SAGE Dictionary of Sociology, p.314

16 Scott, J., \& G. Marshall, Oxford Dictionary of Sociology, p.685
} 
Chinese culture and language and to support cultural exchanges. ${ }^{17}$ These Confucius Institutes allow China to integrate its culture into its foreign policy agenda, which contributes to its aim of changing the perception that China's rise threatens the established international order.

The same is true of Chinese values, which have become significantly integrated within the Chinese foreign policy arena. China's values are an important part of its appeal, due to their alternative nature to those of the US. Chinese values have been built on its history of religion, philosophy, and its history of economic and political subjugation by Western powers. This has influenced its values, and the decisions China has made as a country. China has taken advantage of this history to emphasise its shared anti-colonialist sentiment with other developing states. China's history of being subjected to repeated incursions and repression at the hands of external forces have shaped its values to focus on self-reliance, and suspicion towards the outside world. This has led to China possessing political values that are semiauthoritarian in nature, and emphasise an alternative to the Western "Washington Consensus" approach. China has cultivated political values such as experimentation and innovation, especially when it comes to economic development. Chinese values also include a focus on a "top-down" approach to economic management, in large part due to its authoritarian system. This approach emphasises the crucial role of the state in guiding the economy, both to ensure economic prosperity and to ensure political stability. These values have become very attractive to developing states, which do not want to be held hostage by the Washington Consensus, and also want to maintain political stability within their countries. Jeffrey Garten highlights the increasing attractiveness of Chinese political values when he states that;

"The Chinese economic model could also become an attractive alternative to the free market fundamentalism that the U.S. is so fond of trying to push onto other countries. It hasn't gone unnoticed in Asia that the more highly controlled Chinese economic system survived the late-1990s financial crisis in the region, and is handling the Global Financial Crisis very well, while U.S. disciples such as Thailand and South Korea imploded". 18

The example provided here highlights the increasingly important role that Chinese political values are playing in its foreign policy. The growing importance of

${ }^{17}$ Confucius Institute Online, "Introduction to the Confucius Institutes", 2009, http://college.chinese.cn/en/article/2009-08/29/content_22308.htm (accessed November 21 2012) 18 Garten, Jeffrey E., "China: The Missing Member at the G-8 Table", 2004, http://yaleglobal.yale.edu/content/china-missing-member-g-8-table (accessed November 21 2012) 
Chinese culture and values is evidence of the increasing importance of soft power to the field of Chinese foreign policy. 


\section{Methodology}

This section will identify the research method that was used to gather data for the analysis of China's education scholarships in the South Pacific. To accomplish this, the section will first identify and briefly explain the problem that was solved. Next the chosen research method will be examined, including an identification of the variables involved and an explanation of potential limitations that faced this analysis. Finally, the chosen research method will be justified by identifying alternative research methods that were not chosen and an explanation of why this method was chosen.

The objective of this analysis was to show that China is using soft power as a way to prepare for greater political and economic engagement with distant regions of the world. To accomplish this, the analysis focused on China's provision of education scholarships, to measure how they affected the perception of China held by those outside of the country. This analysis was targeted at the South Pacific, within the time period between 2000 and the present. This allowed for a range of data to be gathered, which widened the scope of the analysis and allowed more data to be accessed.

The analysis within this paper was based on a qualitative model, using data analysis of statistics and a case study approach. These research methods were appropriate for the type of analysis being undertaken, because they were able to identify and examine the extent to which education is enhancing soft power. This was primarily due to the freedom afforded to the case study approach, which enabled the research to focus on the China-Tonga bilateral relationship, rather than a regional focus. There were several variables that had to be taken into account when undertaking this analysis. These variables affected the analysis, because they were largely out of the control of the researcher, so could not be prevented from occurring. These variables included the sensitivity of the subject area, the ability of governments to provide the necessary statistics, and the originality of this research. The most significant of these variables was the sensitivity, because it determined whether or not the Tongan and Chinese governments were prepared to release data for this analysis. This was a major limitation to the analysis of Chinese soft power, along with several others that will be identified. Other limitations that affected this analysis include the originality of the field, the scope for research, and the amount of time that 
was available to conduct research. Since this research was focused on an area that had not been examined before, this limited the access to past research to help guide the analysis. Because of this, the analysis was limited in what it covered. The focus on the South Pacific for this analysis also limited the research, because Chinese engagement with the region is a fairly recent occurrence, which meant that there was a limited range of evidence available to analyse. Finally, the one-year time limit on this thesis reduced the scope of the research.

The decision to choose data analysis and the case study approach as the primary methods of research was made after considering other research methods. These alternative research methods included; survey distribution and interviews. Because these methods focus on gathering attitudes and opinion, they are subject to ethical standards and political consideration from the countries or institutions that are affected by this research. Due to this, data analysis and a case study were chosen as the primary research methods. Apart from the advantage of avoiding potentially sensitive political issues, these methods enable the researcher to take a more intimate focus on the hypothesis. This was because the data could be analysed from a number of different scenarios. It is this freedom and flexibility compared to alternate research methods that made data analysis and a case study the most effective tools for this research.

After taking into account the problem that needs to be solved, the primary research methods and variables involved with these methods, and the reasons why these methods were chosen ahead of alternative options, it can be seen that survey distribution and interviews were the most appropriate ways to collect data for this thesis. 


\section{Chapter Two:}

\section{Literature Review}

\section{Soft Power: a theoretical framework}

The previous chapter explained the concept of soft power and its establishment by Joseph S. Nye. To fully understand the framework, this section will now review Nye's work on the concept, involving an appraisal of the arguments made by Nye, and an analysis of the conclusions and observations made. This will introduce an analytical framework to guide the later review of the academic literature.

\section{Review}

Nye bases his establishment of soft power on three fundamental arguments. These arguments are crucial to the framework because they explain why soft power is effective and necessary in the international system. To properly analyse this, the three fundamental arguments will be examined in detail. These three arguments are; the idea that soft power rests on the ability to shape preferences, it is more effective in similar cultures than widely dissimilar cultures, and that it is able to effectively manage the evolving state of power.

Nye argues in Bound to Lead that the strength of co-optive power lies in its ability to shape the preferences of others. ${ }^{19}$ Nye goes on to argue that soft power "currencies" are important for shaping those preferences that attract states towards others, because they are what drive transactions between states. To analyse the importance of these currencies to Nye's argument, three will be examined in relation to the argument made by Nye. These currencies are; culture, domestic institutions, and foreign policy. Nye formulates that culture is important for spreading soft power because it can attract others when it is similar to the culture of the states it is seeking

${ }^{19}$ Nye, Joseph S., Bound to Lead: The Changing Nature of American Power (New York: Basic Books, 1990), p.31 
to attract. The massive appeal of brands such as Apple, McDonalds and Nike, in countries such as Japan, China and Korea are evidence of the strength of culture as a source of attraction. This use of culture as a driver is significant, because culture is never static, which allows it to adapt to the changing nature of power, which is a significant aspect of soft power. This is because culture exists at several levels, affecting different types of individuals. Nye argues that this is important, because it allows states to attract others through their culture, from the elite level to the level of individuals. ${ }^{20}$ Nye also states that when culture is universalistic in nature it is more effective at attracting outsiders. ${ }^{21}$ US cultural icons like McDonalds, Apple and other big name brands have infiltrated states like China, which have created a demand among newly-emerging middle classes for these products, which are viewed as a status symbol. ${ }^{22}$ This argument made by Nye is significant, because it highlights the advantage that culture holds over more traditional tools for power projection. This is because power has traditionally been developed and projected using economic strength or military might, which is not necessarily effective at creating attraction at multiple levels, whereas individuals and states are exposed to culture at multiple levels. Nye highlights the case of the Vatican, which holds considerable soft power despite having a relatively small military and economic strength. ${ }^{23}$ This suggests that the Vatican draws strength from its culture of Catholicism. This example highlights the importance of culture in shaping preferences, because it attracts at various levels.

The second currency identified by Nye as crucial is domestic institutions. This refers to the values and politics of states, and the impact that they have on soft power. Nye argues that they are important because they create attraction by highlighting the beliefs held by a state or organisation, which affects the level of power they possess. ${ }^{24}$ Nye also argues that domestic politics play a significant role because they can either attract or repel outsiders. The relationship between these two domestic institutions and their impact is important, because these values and policies guide the actions of states, which has an impact on the influence that they are able to develop. Values are

\footnotetext{
${ }^{20}$ Nye, Joseph S., The Future of Power (New York: Public Affairs, 2011), p.84

${ }^{21}$ Nye, Joseph S., Soft Power: The Means to Success in World Politics (New York: Public Affairs, 2004), p.11

22 Goodman, D. "People's Republic of China", in R. Robison and D. Goodman (ed.) The New Rich in Asia (London: Routledge, 1996), p.226

23 Nye, Soft Power, p. 9

24 Nye, Soft Power, p.11
} 
important within the international system because they determine the type of behaviour that is pursued by individuals and states. This is significant, because Nye argues that states are attracted to other states that share similar values to them, and are repelled by those who possess values that are abhorrent to that state. ${ }^{25}$ This affects soft power because it relies on attraction to create the power that states wield within the international system. Nye identifies the US as a state whose values are attractive to others, because they are universalistic in nature. ${ }^{26}$ This suggests that the US possesses increased power due to the way that the values of the US have influenced its decisions. Nye identifies domestic politics as playing a similar role to domestic values in generating soft power. However, domestic politics are much more susceptible to harming a state's image. This is argued by Nye using examples from the history of the US. He states that the US policy of segregation severely undercut its image in Africa, while the policy towards human rights enhanced it in Latin America. ${ }^{27}$ This is significant to the academic literature, because it highlights the importance of domestic politics. The examples used by Nye suggest that domestic politics are important because they influence the way that states are perceived by outsiders. The two examples highlight this because domestic policies introduced by the US had direct impacts on the perception held towards it by outsiders.

The third currency that Nye identifies is foreign policy. The role of foreign policy is important, because it portrays the goals and interests of states towards the outside world. Nye says that the policies pursued by states can reinforce or squander the soft power possessed by that state. ${ }^{28}$ This is because the policies put forward by states can be perceived as hypocritical, arrogant, or indifferent, among other negative perceptions. This is significant, because it suggests that perception plays an important role in the image portrayed through foreign policy. This perception is difficult to control, which is highlighted by Nye when he argues that "soft power may appear less risky than military or economic power, but it is often hard to use, easy to lose, and costly to re-establish". ${ }^{29}$ This statement made by Nye highlights the

\footnotetext{
25 Ibid

${ }^{26} \mathrm{Ibid}$

${ }^{27}$ Nye, Soft Power, p.13

${ }^{28}$ Nye, Soft Power, p.14

${ }^{29}$ Nye, The Future of Power, $\mathrm{p} .83$
} 
importance of foreign policy to soft power, because it dictates the image that is portrayed to outsiders.

The three soft power "currencies" identified by Nye, and analysed in this section, have been shown to be a crucial argument within the academic literature. This is because they have been shown to shape preferences, create attraction and develop an image of states. These arguments have been shown to be significant through the examples provided.

\section{Conclusions}

The conclusions reached by Nye are important to the academic literature, and as such must be analysed and interpreted. The three conclusions reached by Nye that must be analysed are; the importance of soft power will increase, the complex nature of it, and that its rise is not solely due to government actions, which makes it more difficult to wield.

Nye's first conclusion states that changes in the international system mean that soft power will become more important, as the international system evolves. He states that the increasingly globalised world will make power more diffuse, as power is increasingly wielded by NGOs, transnational networks and traditional states. This, Nye argues, makes soft power more important, because it is able to evolve alongside the information revolution and removal of borders, which makes power more fluid. This conclusion is significant, because it highlights its strength compared to the traditional forms of power. The ability to be developed and projected by non-state actors can be considered a significant contributor to Nye's conclusion. This is because as access to power becomes more available, it will become more important, because more groups will look to access soft power, making it more valuable. Nye highlights the role of corporations, terrorist networks, and non-profit organisations as examples of its use by non-state actors. ${ }^{30}$ This example is important to the conclusion reached by Nye, because it highlights the types of organisations that are benefiting from the diffusion of power. This conclusion suggests that the current literature has identified an area of research that has not been examined by scholars to date.

${ }^{30}$ Nye, The Future of Power, p.83 
The second conclusion made by Nye argues that many variables exist that both constrain and enhance a state's soft power, and that these variables determine the success or failure of a states' efforts. Nye concludes that states must make use of multiple communications channels, have a dominant culture and values, and have domestic and foreign policies that enhance their credibility. ${ }^{31}$ He suggests that the US and European states may benefit from these variables. ${ }^{32}$ This conclusion is significant to the academic literature, because it suggests that soft power is reliant on certain circumstances playing out. These circumstances can include democracy, human rights, military prowess, and the strength of an economy can all contribute to the enhancing or limiting of a state's power. This suggestion is important, because it highlights its complicated nature. This suggests that it should be interpreted as higher risk, but with a higher reward than the likes of military or economic power. This is evident if the argument put forward by Nye is compared to arguments put forward for military and economic power. Advocates of hard power argue that power is attained through the use of coercion, either by military strength or economic inducements, such as financial aid. Nye has countered that while these forms of power are still important within the international system, the evolving nature of power means that they are not able to decide all situations. ${ }^{33}$ Economic power rests on political frameworks, which means that in times of great uncertainty, frameworks can fail. ${ }^{34}$ Nye uses the example of the 1997 Asian financial crisis, where previously strong Asian economies were struck by financial crisis, which resulted in emerging economies such as Russia and Brazil being undercut. ${ }^{35}$ Nye argues that because soft power relies on perception and attraction, it is more concerned about consequences and side-effects from the actions that states take. Nye argues that this reliance on perception and attraction means that it is dependent on a number of conditions to be successful, such as culture, values and policies. This suggests that despite it being riskier to use than more traditional forms of power, the benefits are greater than those from military or economic power.

\footnotetext{
31 Nye, Soft Power, p.31

32 Ibid

33 Nye, The Future of Power, p.49

34 Ibid

35 Nye, The Future of Power, p.55
} 
Nye's third conclusion, that the rise of soft power is not due solely to government actions, is significant to the academic field because it highlights the key difference it possesses, compared with hard power. In his work, Nye concludes that soft power is a social and economic by-product rather than a result of official government action. This conclusion reached by Nye is a significant contribution to its understanding, and of power in general, because it identifies and expands on the relationship of society and the economy with power, not as primary creators but as influencers. Nye's conclusion suggests that it occurs as a by-product of interactions, which is a new insight into the concept of power in international relations. This is because the academic debate on power has until recently focused on the role of the state in creating and projecting power within the international system. Nye's focus on "currencies", such as culture, values and institutions, are important to this contribution because they are examples of how influence fuels soft power rather than direct actions. This suggests that Nye's contribution to the academic debate on power has been significant, because it seeks to identify an aspect of power that is not widely recognised or analysed by the academic literature. Nye's conclusion has also gone some way to disproving claims made by sceptics, who claim that attraction and imitation are not forms of power. ${ }^{36}$ The conclusion that Nye reaches is significant in highlighting shortcomings related to this criticism, because it provides evidence that social and economic by-products are playing a role in creating power. The US saw its soft power increase in China due to the transformation of the Big Mac into a status symbol among middle-class Chinese. ${ }^{37}$ Chinese will often spend as much as a fortnight's income for one, due to its perception as being "chic". ${ }^{38}$ This example highlights the role played by society and the economy in developing soft power in other states. This is because the economic power of McDonalds as a global brand saw it spread to China, and its status saw it become a source of attraction among Chinese.

The conclusions made by Nye, that the importance of soft power is increasing, certain variables determine its success or failure, and that it is created by social and economic by-products rather than direct government action, have been shown to have made significant contributions to the academic debate, because they have identified areas of research previously unexamined, have identified benefits

\footnotetext{
${ }^{36}$ Nye, Soft Power, p.15

37 Goodman, "People's Republic of China", p.226

$38 \mathrm{Ibid}$
} 
previously disregarded, and shown that direct action is not necessary to generate power.

The impact of alternative schools of thought on soft power

The theoretical framework behind Nye's theory has been influenced by a number of other important theories in the field of international relations. These theories are closely related to soft power, in the explanations they provide for how the international system works, and for the role that actors play in the system. These explanations are important, because they provide important insights into the role of it within the international system. To better appreciate this, the alternative theories will be examined, to show how they improve understanding. Following this, the main criticisms will be reviewed, to highlight the shortcomings of this concept, and why they are important to the academic debate.

\section{Alternative theories}

There are a number of theoretical frameworks in the field of international relations that contribute to the understanding of soft power. These theories are important, because they explain several aspects of it that are at odds with more traditional aspects of power. To better appreciate this, the section will review the academic literature on constructivism, complex interdependence theory, and the nature of power in global governance. The purpose of this section is to examine how these theories provide explanations for the role that soft power plays within the international system and why they matter.

Constructivism, complex interdependence theory, and the role of power all provide differing explanations for the existence and role of soft power in the international system. All these explanations are significant for the academic literature, because they enhance the understanding of the concept, and make it possible for greater scholarship in areas that have not previously been understood.

Constructivist theory is important to the academic debate, because it provides an explanation for its existence in the international system. Constructivism argues 
that concepts in the international system, such as power, are socially constructed by actors within the system, rather than simply existing as part of nature. ${ }^{39}$ Constructivist scholar Wendt argues in his seminal work, Social Theory of International Politics, that the role of society in shaping the identities of individuals and the role of domestic politics in foreign policy suggests that the neo-realist belief in structure influencing states' behaviour is not necessarily the correct assumption. ${ }^{40}$ This idea is important to the concept of soft power, because it provides an explanation for its existence. The role of states, NGOs and individuals in generating power is explained by constructivism's belief in social construction of ideas and concepts in the international system. This suggests that soft power's reliance on culture, norms and values, and policies are derived from the socially constructed nature of the international system. This important, because it suggests that it is a result of the socially constructed nature of the international system.

Keohane and Nye established the idea of complex interdependence as a response to the increasing interconnectedness of the international system. This theory of complex interdependence is important for the understanding of soft power, because it provides greater understanding of its role. Keohane and Nye argue that states and their fortunes are inextricably tied together due to the growing economic and political ties that exist between them. ${ }^{41}$ This interconnectedness has resulted in states becoming reliant on each other in a number of areas. Keohane and Nye state that this has both positive and negative outcomes for states. The oil shocks of the 1970s had a negative impact on Western states such as the US, Japan, and Western Europe, as OPEC member states initiated an oil embargo. ${ }^{42}$ Complex interdependence is important, because it provides insight into the role that attraction plays. As states become more interconnected, the role that image and reputation play becomes more significant. This has led to states becoming more focused on ensuring that they maintain a positive image on the world stage. Soft power has emerged from this, becoming a major factor in the nature of state-to-state relations, especially when influencing the attitudes and opinions of citizens. This shows that complex

\footnotetext{
${ }^{39}$ Wendt, Alexander, Social Theory of International Politics (Cambridge: Cambridge University Press, 1999), p.1 
interdependence is important to the academic debate, because it explains how the nature of the international system has enabled soft power to assume an important role in the foreign policy arsenal of states.

Power is seen as a crucial aspect of international relations, especially among realist scholars. The dominance of realism in the scholarly field of international relations has led to a focus on power as a tool used, and sought, by states to wield over other states. But it is more important than this; it influences the very system that states exist within. It has the ability to shape state behaviour, which is a powerful tool in international relations. This debate has been brought to light by Barnett and Duvall, who argue that the many different forms of power must be understood, to better understand how outcomes are reached and how states are enabled or constrained in their actions. ${ }^{43}$ It is argued that by doing this, the understanding of global governance can be reshaped. Barnett and Duvall identify four main types of power; compulsory, institutional, structural, and productive power. ${ }^{44}$ This is important for the debate because soft power can be attributed most closely to a form of productive power, due to its role in shaping the subjectivities of citizens in other states. It is an important type of power than has not been adequately examined, despite its important role in providing new understanding of global governance. Barnett and Duvall's work is important, because it identifies the complex nature of power, and provides a counterargument to the dominance of realism. It also identifies the role that aspects of soft power have in shaping global governance.

These theories have been shown to contribute to the academic debate, whether in terms of the role that soft power plays in the international system, or why it came to exist. This is important for the later examination of Chinese soft power, because it provides greater insight into how it is used and adapted by states as part of their foreign policy

\section{Criticisms of soft power}

Soft power has attracted criticism from a number of international relations scholars, most prominently from the realist school of thought. These criticisms are

\footnotetext{
${ }^{43}$ Barnett, Michael, and Raymond Duvall, "Power in Global Governance", in Michael Barnett and Raymond Duvall (ed.), Power in Global Governance (Cambridge: Cambridge University Press, 2005), p.3 44 Ibid
} 
important to the academic debate, because they identify areas where it is in competition with other theories, and it identifies potential weaknesses in the theoretical framework. To better appreciate these criticisms, the section will first look at what the criticisms made by neo-realist, offensive realist, and structuralist scholars are. Then it will explain why they are important to the academic field.

Neo-realist scholars criticise soft power for several reasons. The main reason it is criticised is because neo-realists posit that actors are only responsible for two types of incentive; economic incentive or force. This is argued by Waltz in Man, the State, and War, and Theory of International Politics. In these works, Waltz argues that economic incentives and force are used by states to ensure their own survival. Neorealism states that force is necessary to ensure the balance of power between states, and to ensure their survival in an anarchic system. Waltz states that because of this, economic incentives and military force are effective tools for maintaining and developing power. ${ }^{45}$ Because of this emphasis on hard power tools, neo-realist scholars criticise soft power for being ineffective and vague, and a reflection of hard power. Waltz emphasises this when he uses the example of Russian exposure to British civilisation. He uses this example to explain that British use of military force was responsible for the widespread cultural change in Russian society. 46 This example is important, because it highlights criticism by neo-realists that soft power is actually a reflection of hard power.

Offensive realism was established as a major school of realist thought in the early twenty-first century. It differs from neo-realism in that it holds that states strive to become hegemons, by pursuing aggressive policies to maximise their power. ${ }^{47}$ This differs from defensive realism in that it holds that states seek defensive policies aimed at ensuring their own survival, or maintaining the status quo. ${ }^{48}$ Mearsheimer argues that states can never been certain of the intentions of others, and possess offensive military capability to maximise their power. This argument put forward backs up his criticism of soft power, that international institutions are incapable of

\footnotetext{
45 Waltz, Kenneth, Theory of International Politics, (New York: Random House, 1979), p.126

${ }^{46}$ Waltz, Kenneth, Man, the State, and War, (New York: Columbia University Press, 1954), p.59

${ }^{47}$ Mearsheimer, John, The Tragedy of Great Power Politics, (New York: W.W. Norton \& Company, 2001), p.33

48 Waltz, Theory of International Politics, p.190
} 
convincing states to stop acting as short-term power maximisers. ${ }^{49}$ He goes on to argue that institutions merely reflect the current balance of power in the international system. ${ }^{50}$ These two statements underpin the offensive realist critique, because soft power theory relies heavily on international institutions to generate and transmit power. Mearsheimer's argument that institutions merely reflect the balance of power is important, because it discredits the idea that international institutions can generate soft power for other states.

Structure is an important aspect of realism, because some realist scholars argue that structure is a constraint on state behaviour. Structure has been used as a criticism of soft power by international relations scholars, as it is argued that soft power currencies are merely embedded within the established structure of the international system. Niall Ferguson pushes this criticism, arguing that currencies like culture, values and norms are merely part of the existing structure of the international system. To highlight this argument, Ferguson uses the British and American empires as examples. He argues that the use of media, sport, literature and other cultural tools by the US to develop soft power is merely a continuation of the British Empire's use of the same tools to develop the same attraction. ${ }^{51}$ He goes on to argue that it is merely a continuation of the "Anglicisation" policies that dominate the international system. ${ }^{52}$ This argument underpins Ferguson's critique, because it provides evidence that soft power currencies may simply be aspects of the established structure of the international system, rather than tools to be used by states to develop soft power.

The critiques put forward by various realist scholars have contributed to the academic debate in many important ways. The claims of vagueness and ineffectiveness, the lack of trust among states, and the structure of the international system have asked questions of the theoretical framework that require examination to better understand the intellectual framework of soft power.

\footnotetext{
${ }^{49}$ John J. Mearsheimer, “A Realist Reply", International Security, vol. 20, no. 1, 1995, p.82 $50 \mathrm{Ibid}$

${ }^{51}$ Ferguson, Niall, Colossus: The Rise and Fall of the American Empire, (London: Penguin Books, 2004), p.20 
Claims made by critics that it is a vague and ineffective concept are important, because they underline a major weakness in the theoretical framework. This weakness concerns the lack of solid tests to measure the extent of soft power, and the effectiveness of it. This is an important issue, because it highlights the problems it faces in competing with rival forms of power for legitimacy. Hard power's obvious visibility and ability to be measured means that it possesses more legitimacy. Soft power's reliance on opinion polls as a primary measure of effectiveness has been dismissed by scholars such as Ferguson, making it subject to greater criticism. ${ }^{53}$ Its effectiveness has also been criticised, which is important because it asks questions of its success rate. This is due to some notable failures to influence outcomes desired by superpower states. The US is promoted by soft power scholars as an example of a state that wields a great deal of power in other countries, especially among its allies. Despite this, it was unable to obtain the votes of Mexico or Chile in the UN Security Council for its 2003 invasion of Iraq. ${ }^{54}$ This is important, because it shows that soft power has not yet demonstrated that it is able to consistently translate efforts into results, which is necessary to improve its legitimacy among states.

The critique by scholars rests on the belief that states cannot trust each other, which makes it impossible for international institutions to be used to develop soft power. This critique is important to the field, because international institutions are a central aspect of the theoretical framework. This criticism is significant, because proponents argue that these institutions play an important role in developing and projecting soft power. If international institutions merely reflect the dominant state in the international system, then it casts doubt on the ability of rising states to use these institutions to develop their own power. This criticism offered by scholars raises a question; if institutions are controlled by dominant states, are they developing soft power, or are they merely reflecting the polarity of the international system? This is important, because it places into question the effect that international institutions actually have, as claimed by proponents of the theory. This critique has made an important contribution to the academic debate, because it identifies a serious shortcoming in the theoretical framework.

\footnotetext{
53 Ferguson, Colossus, p.21

54 Nye, Soft Power, p.16
} 
Realist critics have argued that the currencies identified by Nye as being necessary are simply aspects of the existing structure of the international system, not tools for developing soft power. This critique is important, because it discredits the main features of the concept. The claim that culture, values and norms, and policies are simply parts of the existing structure of the international system suggests that soft power is not an independent entity, but a by-product of the international system itself. This is important, because it challenges the idea put forward by Nye that culture, values, norms and policies can be used by states to generate power.

The alternative theories that reinforce the theoretical framework, and the critiques offered by realist scholars, are important contributions to the academic debate. Constructivism, complex interdependence theory, and the debate surrounding power have all been highlighted as making significant contributions to the understanding of soft power, either by providing greater insight into the role that it plays, or why it exists. The critiques examined have highlighted important shortcomings that exist in the theoretical framework. These critiques should be addressed by the academic literature, to enhance its legitimacy and to expand understanding of the theory. 


\section{Chinese soft power: a framework for a harmonious world}

The aftermath of the Tiananmen Square massacre saw China reconsider how it approaches its governance, with a view to improving its image among other states. As part of this, China has sought to make use of certain aspects of soft power, altering and adapting them to suit its needs. This has seen several tools of soft power be transformed by the Chinese regime, adopting Chinese characteristics to them. ${ }^{55}$ China believes that its soft power is different from Nye's definition, because it features its own characteristics and is embedded in Chinese traditional culture and ideology. ${ }^{56}$ This reinterpretation is due to the widely held belief among Chinese policymakers that it has always been an indispensible part of its comprehensive national strength. Comprehensive national strength is a uniquely Chinese concept that is not evident in the West. ${ }^{57}$ It encompasses several facets of society to calculate a state's strength. These facets include politics, economy, military, culture, values and other factors. ${ }^{58}$ China has interpreted soft power in this way because it seeks to become a global power, and to ensure the success of socialism over capitalism. ${ }^{59}$ To do this it realises that it must formulate a positive image among other states. This section will examine the academic literature regarding China's interpretation of soft power and its use within the international system. The nature of Chinese soft power will be examined to provide an overview of the subject area. The literature will then be reviewed to provide greater understanding of the subject.

\section{Overview}

China has only recently been exposed to the great international relations debate. Since the opening up of China in the 1970s, Chinese elites were quickly exposed to the new concept of soft power. It has been adopted by the Chinese government as a way to create a favourable image for itself, and to reassure other states that its rise is peaceful. To properly analyse the literature on Chinese soft

\footnotetext{
55 Ding, Sheng, The Dragon's Hidden Wings: How China Is Rising with Its Soft Power (New York: Lexington Books, 2008), p.28

56 Ibid

57 Ibid

58 Ibid

59 Ibid
} 
power, the overall arguments must be explained. To accomplish this, the explanation will be split into three thematic sections relating to the theory and Chinese policy: China's domestic values and politics, China's culture, and its foreign relations.

Top-down soft power is heavily influenced by the domestic values and politics of states who are wielding it. The literature says that this has had a significant impact on China's efforts at enhancing its soft power, both positively and negatively. It has identified that Chinese domestic values have had a positive effect. China's model of economic development, often referred to as the "Beijing Consensus", is identified as a major source of soft power for China. This is because of the success it has had, which can be attributed to the process of controlled decentralisation and gradual liberalisation. ${ }^{60}$ The field argues that this has created soft power because developing states are attracted to this model of economic modernisation. Russian President Vladimir Putin and Indian leader Manmohan Singh have both complimented the Chinese model and suggested it be used in parts of their economies. ${ }^{61}$ This attraction can also be attributed, in part, to the growing backlash against the failed neoliberal model forced by the West on developing states. It also highlights China's improvements in social policy as a contributing factor to China's soft power. ${ }^{62}$ Gill and Huang state that it can be seen in the results of opinion polls conducted within the Asian region. They cite BBC surveys which show China's reputation on the increase in neighbouring states and in Southeast Asia, as the US's reputation declines. ${ }^{63}$ China's domestic politics can also be identified as having harmed its soft power, due to the lack of democracy and human rights abuses committed by the state. The literature goes on to explain that China's gains are being undermined by its lack of concern for democracy or human rights, which Nye says play a crucial role in influencing how others perceive a state. It argues that China's refusal to consider democratic reforms or human rights improvements has resulted in China being viewed negatively by outsiders, which has proved harmful. ${ }^{64}$ Gill and Huang argue that the authoritarian political system, rampant corruption, and lack of human rights consciousness all pose

\footnotetext{
60 Ding, The Dragon's Hidden Wings, p.84

61 Gill, Bates, and Yanzhong Huang, "Sources and Limits of Chinese "Soft Power", Survival, vol.48, no. 2, 2006, p. 20

62 Ding, The Dragon's Hidden Wings, p.84

${ }^{63}$ Gill \& Huang, "Sources and Limits of Chinese "Soft Power", p.24

${ }^{64}$ Holyk, Gregory G., "Paper Tiger? Chinese Soft Power in East Asia", Political Science Quarterly, vol. 126, no. 2, 2011, p.243
} 
serious obstacles to China's soft power. ${ }^{65}$ China's more aggressive regional security policies post-2009 has also posed obstacles, due to the threatening nature of their actions.

Culture has become an integral part of China's soft power, as it seeks to improve its image on the world stage. Prior to its opening up, China did not focus its efforts on improving its international image. The need to modernise the Chinese economy saw greater attention placed on ensuring that China was viewed positively by the outside world. This need for China to be viewed positively by the outside world led to a debate around the need for a "peaceful rise". It is argued that China has placed an emphasis on its culture as a way to educate the outside world about its rise and to allay concerns of neighbours and other states about its rise to a global power. China has sought to focus on a number of areas where Chinese culture has historically been strong. These include education, tourism, and the Chinese language. Education has proved increasingly successful at improving China's image globally, and its soft power resources within the international system. One such way that China has spread its influence across the globe is through the establishment of Confucius Institutes, and through educational exchanges both to and from China. Confucius Institutes have been established to educate others about China and its culture. Ding states that the objective of the institutes is to strengthen the "understanding, opportunities and bonds between individuals, enterprises, communities and institutions", in their home country with the Peoples' Republic of China. ${ }^{66}$ The author argues that this is significant because Chinese culture has become popular again, which has resulted in an increased desire to take advantage of the demand for access to Chinese education. ${ }^{67}$ The second way that China has used education to increase its soft power is through educational exchanges to its country. China has become an increasingly attractive destination for students wanting to study at university, especially in the fields of business and science. The attractiveness of China's culture and its burgeoning economy is attracting foreign students to its tertiary institutions over those in other states. ${ }^{68}$ The enrolment of foreign students in China saw a

\footnotetext{
65 Young Nam, Cho, and Jeong Jong Ho, "China's Soft Power: Discussions, Resources and Prospects", Asian Survey, vol. 48, no. 3, 2008, p.472

${ }^{66}$ Ding, The Dragon's Hidden Wings, p.120

${ }^{67}$ Ding, The Dragon's Hidden Wings, p.121

${ }^{68}$ Ding, The Dragon's Hidden Wings, p.71
} 
tremendous increase between 1995 and 2004, rising from 36,855 to $110,844 .{ }^{69}$ The authors argue that the significance of this lies in the comparison with education exchanges in the US. The authors state that at the same time that Chinese educational power has been increasing, the educational attractiveness of the US has been decreasing. During the 2003/04 academic year foreign enrolments in the US decreased by 2.4 percent, the first drop in three decades. ${ }^{70}$ China has also used tourism to boost its cultural attractiveness. Tourism to and from China has increased the understanding of China and Chinese peoples' understanding of other parts of the world. This has contributed to China's soft power because it portrays a wealthier, more confident class of Chinese citizen. ${ }^{71}$ This in turn influences tourists to visit China, due to the attractiveness of its culture and history. China's status as a major cultural centre of Asia is in large part the reason for China's attractiveness as a tourist destination. ${ }^{72}$ Ding and Saunders state that between 1980 and 2004 China saw the total number of in-bound non-Chinese tourists increase nineteen-fold..$^{73}$ The examples used reinforce the argument they put forward, because they show that culture has become an integral part of Chinese foreign policy, because it portrays a positive image of China and allays fears about its rise that may be held by outsiders.

Foreign policy plays a significant role in soft power, due to its role as the voice of states within the international system. This means that the foreign policies adopted by states can either harm or improve their international standing. China has used its foreign policy to generate a positive image of itself, particularly in regions of the world that have been ignored by the West. The authors identify three major themes that dictate China's foreign policy initiatives; these are chequebook diplomacy, visit diplomacy and participation in international organisations. These three themes are particularly focused on the hard power aspects of Chinese foreign policy, particularly the role of chequebook diplomacy. China has placed particular focus on its use of "chequebook diplomacy". Chequebook diplomacy is the foreign policy practice of using financial aid or economic development to gain diplomatic

\footnotetext{
${ }^{69}$ Huang, Yanzhong, and Sheng Ding, "Dragon's Underbelly: An Analysis of China's Soft Power", East Asia, vol. 23, no. 4, 2006, p. 26

70 Gill \& Huang, "Sources and Limits of Chinese 'Soft Power'”, p.19

71 Ibid

72 Huang \& Ding, “Dragon's Underbelly”, p.27

73 Ding, Sheng, and Robert Saunders, "Talking up China: An Analysis of China's Rising Cultural Power and Global Promotion of the Chinese Language", East Asia, vol. 23, no. 2, 2006, p.16
} 
favour from smaller states. Kurtlantzick argues that China uses chequebook diplomacy to portray itself as an alternative force to the likes of the US. This is primarily due to China's willingness to act as a silent partner in the affairs of the states it provides aid to. The primary argument is that China provides aid to states that officially recognise it with little to no conditions, and without concern in regards to the domestic politics of recipient states. ${ }^{74}$ The literature argues that China's decision to treat the states it provides aid to as equal partners has enhanced its soft power. ${ }^{75}$ This is because China respects their sovereignty and independence, which differentiates China from Western powers, who attach good governance conditions to their aid. ${ }^{76}$ This attitude by China has attracted many developing states because of the more equal treatment that they receive from China, compared with the neoWestphalian Western foreign policy. The literature goes on to explain that this can be attributed to China's emphasis of its shared history of colonial oppression with states like those in Africa. ${ }^{77}$ This has proven an advantage to China in enhancing its soft power in regions like Africa, due to its ability to find common ground at the expense of the West. The author does however also highlight the negative impact that Chinese foreign policy has had on its soft power. Liang explains that China provides development assistance to African states like Zimbabwe and Sudan, despite human rights violations and a lack of democracy. ${ }^{78}$ This willingness to ignore the domestic politics of the states it is courting has potentially harmed its soft power, because it has brought about negative publicity towards its attempts to develop an image of China as a responsible world power. ${ }^{79}$ China has continually foiled the West's attempts to force sanctions on Sudan over its human rights abuses, as it supplies almost five percent of China's oil. 80 This stance taken by China has caused Western

\footnotetext{
${ }^{74}$ Guttal, Shalmali, "Client and Competitor: China and the International Financial Institutions", in Dorothy-Grace Guerrero and Firoze Manji (ed.), China's New Role in Africa and the South (Oxford: Fahamu Books, 2008), p.22

75 Ding, "Harmonious World", p.112

${ }^{76}$ Sautman, Barry, and Yan Hairong, "Friends and Interests: China's Distinctive Links with Africa", in Dorothy-Grace Guerrero and Firoze Manji (ed.), China's New Role in Africa and the South (Oxford: Fahamu Books, 2008), p.99

77 Ding, The Dragon's Hidden Wings, p.139

78 Liang, Wei, "New Africa Policy: China's Quest for Oil and Influence", in Sujian Guo and Jean-Marc Blanchard (ed.), "Harmonious World" And China's New Foreign Policy (New York: Lexington Books, 2008), p.165

79 Ding, "Harmonious World", p.113

80 Wang, Yiwei, "Public Diplomacy and the Rise of Chinese Soft Power", The Annals of the American Academy of Political and Social Science, vol. 616, no. 1, 2008, p.265
} 
media to negatively portray the country. ${ }^{81}$ This has been shown to have significant negative impact upon China's quest for a better understanding of its objectives and its international standing.

The academic literature on Chinese soft power has identified its relevance to the debate surrounding soft power. The focus on the three areas of domestic values and politics, culture, and foreign policy have been important for the literature because it has allowed the arguments to be separated to provide a clear debate on its benefits and costs to China.

Review

The academic literature has significantly covered China's use of soft power, as part of its rise to great power status. This section seeks to review this, to examine the arguments made and their significance, and to analyse and interpret the conclusions and findings made. To do this, the first section will focus on the arguments made, followed by a second section focussing on the conclusions and findings reached.

The previous section highlighted the main arguments of the academic literature concerning the three major parts of China's soft power policy. The argument made towards China's domestic values and policies says that China's development model has drawn favour from many developing states, due to its lack of conditions put on assistance, but that this is also being harmed by China's lack of progress towards democracy and human rights domestically. The first part of the argument, that China has enhanced its soft power through the development model that it adopted to grow its economy and its attitude to aid distribution, has proven to be very convincing. This is because the author bases the argument on large amounts of evidence from a cross-section of the international system. The wide use of evidence has enhanced the argument because it shows that China's image is enhanced across the globe, rather than confined to a specific area. This is shown by the evidence provided from Africa and Latin America. Sautman and Hairong explore the decision by African states to turn to China's development model as an alternative to the Washington consensus, which they explain is due to the conditions attached to

81 Ibid 
Western development assistance. ${ }^{82}$ This trend is also evident in Latin America, as Ding argues that Latin American countries are attracted to the Chinese development model, in part by the prevalence of left-leaning political parties, but also due to the attractiveness of China's model. ${ }^{83}$ The links made between examples from different regions highlight the convincingness of the argument that China's development model has enhanced its soft power, because China's growing support can be found in different parts of the world. This wealth of evidence provided to back up this argument can also be seen in the argument that China's provision of development assistance has also enhanced its soft power, due to the lack of conditions and requirements attached to this aid. This is due to the wealth of statistics provided that shows the importance of Chinese aid to its power in the international system. Guttal uses statistics related to China's aid and development assistance distribution to show that China is gaining considerable support from its provision of "no-strings-attached" aid. This can be seen in the comparison of China's aid programmes in Asia and Africa. Guttal explains that China provides large amounts of aid to the Asian Development Fund and Africa Development Bank for aid projects in the region. ${ }^{84}$ This comparison is important because it shows that there is significant evidence supporting the arguments made by the authors.

The argument made that the soft power gains made by China's development model are being harmed by its domestic politics has made a significant contribution to the academic debate. This is because the role that domestic politics play compared to domestic values is a significant aspect of soft power, but there has been little comparison of the effect that the two have on each other. The analysis highlights the problems facing China's domestic politics, largely due to the lack of action towards democracy and human rights, which it argues is harming China's image. This is significant, because the harm being caused by China's domestic politics is directly affecting the gains made by its domestic values, such as its development model. Gill and Haung argue that the soft power gains being made by China are being undermined by its political system, human rights record and growing economic and military power. 85 This example highlights the importance of the comparison made by

\footnotetext{
${ }^{82}$ Sautman \& Hairong, "Friends and Interests", p.98

83 Ding, "Harmonious World", p.119

${ }^{84}$ Guttal, "Client and Competitor", p.22

85 Gill \& Huang, "Sources and Limits of Chinese 'Soft Power'”, p.28
} 
the literature. This is because it shows the problems posed when states have attractive domestic values, like China's development model, but its domestic politics are not viewed positively by other states within the international system.

The academic literature has developed the argument that China has used its culture to improve the image it projects to outsiders. The argument is objectively reasoned and has been supported by considerable statistical evidence. The objectivity of this argument can be attributed to the type of evidence used to support it. This is because the evidence used allows the authors to take a step back and let the statistics guide the argument. This can be seen in the way that the statistics are used in the arguments put forward. The statistical evidence shows both positive effects of Chinese culture and negative effects, both of which are highlighted and examined. The literature uses statistics showing the numbers of people coming to China to study and for tourism to highlight the power of China's culture in enhancing its soft power. ${ }^{86}$ These statistics suggest that China has benefited from the attractiveness of its culture in the form of increasing tourist and student numbers. It also identifies a growing fear of China's rise that is not being allayed by China's culture. Holyk identifies a growing fear held by East Asian countries towards China's rise. He states that seventy-four percent of Japanese and South Korean citizens surveyed, identified themselves as "very worried" or "somewhat worried" that China will become a military threat. ${ }^{87}$ These two examples highlight the importance of statistics in ensuring the objectivity of the argument put forward, because it has highlighted the traditional concerns of rising powers.

The argument put forward that China is using its foreign policy to project a positive image is not convincing. China's relationships with dictators and human rights abusers undermine the argument made by the authors. The literature has argued that China's foreign policy has focused on reaching out to other states, and embracing multilateralism, which it is argued is a ploy to dispel concerns over its intentions. This argument is supported by evidence, like China's decision to reform much of its legal and economic institutions so it could join the WTO. 88 The authors use this argument to highlight the way that this has enhanced China's soft power. Despite this, evidence is identified that contradicts the argument that China's foreign

\footnotetext{
${ }^{86}$ Huang \& Ding, "Dragon's Underbelly", p.26

${ }^{87}$ Holyk, "Paper Tiger?", p.239

88 Ding, The Dragon's Hidden Wings, p.100
} 
policy is enhancing its soft power. China's willingness to cooperate with undemocratic regimes is harming its standing in the international system. Gill and Huang argue that China's friendship with dictatorships has created a legitimacy problem, which threatens its soft power status. ${ }^{89}$ Gains made by China through can be eroded when it supports dictators who oppress its peoples, in countries it is attempting to attract. The examples highlighted here show the significant contradiction in arguments made in regards to China's foreign policy, which has challenged the convincingness of the argument used in the literature.

The conclusions reached regarding Chinese soft power is in need of analysis, as it provides an important insight into the wider field and its applications to other parts of the world. To this end, this section will focus on the three major conclusions reached by the authors. The three conclusions made are that; China has made large gains in its soft power, further development will be constrained by domestic factors, and that China's soft power is reliant on other states within the international system. These conclusions will be analysed and reviewed to identify their contributions.

The academic literature concludes that China has made significant gains in its soft power over the last two decades. This conclusion is significant, because of the implications it has for future analysis. This is because the argument that China has made significant gains shows that soft power analysis can be applied to other nondemocratic regimes. It is concluded that China's use of a combination of culture and domestic values has enabled it to develop a positive image on the world stage, by using its culture to educate outsiders and its domestic values to attract them. The literature concludes that this combination has proven very successful for China, due to the increase in its soft power. It also provides an insight into the application of soft power analysis to non-democratic regimes, because of the challenge that China faces in enhancing its soft power while restricting access to democracy and human rights. The relationship between China's domestic values and its domestic politics provides an important comparison because it shows that despite conflict between politics and values, soft power can still be developed. This provides opportunities for it in other states to be examined, because of the relationship between culture and domestic values. This is significant because it allows the international system to be examined

${ }^{89}$ Gill \& Huang, "Sources and Limits of Chinese 'Soft Power'", p.28 
from a different perspective. Ding concludes that China's use of soft power has allowed it to reposition its geopolitical alliances in a way that aids its ascent as a great power, due to its new diplomatic approaches that have brought it favour among states that have traditionally been wary of its rise, such as South Korea. ${ }^{90}$ This example highlights how soft power is changing the way that states form alliances and grow their power. Because of this, the conclusion made that China has experienced significant gains shows the potential for soft power to be used as an alternative form of analysis of the international system.

The second conclusion made is important because it suggests that soft power leads to democratisation. This is because it concludes that China's future prospects are constrained by factors like its authoritarian political system. It concludes that China's authoritarian system is not widely attractive, nor is its legal system, which will constrain China's ability to compete with established powers such as the US. ${ }^{91}$ The nature of the Chinese state and its legal system is severely damaging the topdown nature of China's soft power development. This conclusion suggests that any gains may not be enhanced without a reciprocal gain in democratisation. This is significant because it suggests that China's focus on soft power will not be effective in the future unless it democratises to some degree. Ding and Saunders argue that unless China modernises its political system to adopt more democratic aspects it will only be attractive to countries in corners of the world where respect for democracy and human rights is not valued. ${ }^{92}$ It also states in its conclusions that China cannot compete with the other great power, the US, without some level of democratisation, because the US is perceived very positively in its attitude towards democracy and human rights. ${ }^{93}$ This example highlights the significance of the conclusion reached in regards to China's continued soft power development, because China cannot attract a wider audience of states unless it is viewed positively by states that value democracy and human rights, which constrains the effectiveness of the soft power it is attempting to develop.

The third conclusion reached is that China's continued rise will largely be determined by the role it takes internationally. The literature concludes that the fate

\footnotetext{
${ }^{90}$ Ding, The Dragon's Hidden Wings, p.168

${ }^{91}$ Gill \& Huang, "Sources and Limits of Chinese 'Soft Power"', p.30

${ }^{92}$ Ding \& Saunders, "Talking Up China", p.22

${ }_{93}$ Ding \& Saunders, "Talking Up China", p.23
} 
of China's soft power rests on whether or not it chooses to continue with its increasingly cooperative stance on the international stage. ${ }^{94}$ China's integration into international governance has been identified as a significant factor in its increasing soft power. It suggests that unless China continues to become more integrated into international organisations it will risk harming its soft power. This is significant, because it highlights the relationship between soft power and cooperation in international organisations. Ding argues that China has become more involved in international organisations such as ASEAN and the WTO to counter the perception that a rising China is a threat. ${ }^{95}$ Ding goes on to conclude that this has proved a significant aspect of China's drive to create a "harmonious world" conducive to its rise. ${ }^{96}$ This is an important contribution to the academic field because it shows the relationship between international cooperation and soft power is important to enhance the perception of a state in the international system.

The conclusions reached are significant to the academic field surrounding China's use of soft power. This has been shown through the examination of three conclusions. These are; China's soft power gains, the impact of domestic factors on future soft power development, and the reliance of China's soft power on the international system. These three conclusions have all highlighted the significance of China's use of soft power and the implications it has on future development.

\section{China in the South Pacific: new kid on the block}

China's relationship with the South Pacific is a relatively recent addition to the academic field. This is due in large part to the diplomatic rivalry between China and Taiwan, which was played out between the two countries in the South Pacific for almost two decades. This rivalry saw China provide large amounts of no-stringsattached financial aid to the region, and vast infrastructure projects. However, since their diplomatic truce in 2008 China has expanded its relations in the region. This expansion has included a growing focus on soft power initiatives by China. The South Pacific will provide a useful case study for China's increasing adoption of soft power

\footnotetext{
${ }^{94}$ Huang \& Ding, "Dragon's Underbelly, p.472

95 Ding, "To Build a "Harmonious World", p.117

${ }_{96}$ Ding, "To Build a "Harmonious World", p.122
} 
initiatives, because it is not a very widely understood area of China's foreign relations. The scholarship on China-South Pacific relations is limited, and that scholarship that does exist is largely focused on its prominent relationships, such as with Fiji.

\section{Overview}

The academic literature on China's engagement with the South Pacific has focused on three key themes. These three themes relate to China's objectives in the region, and are considered important to the analysis of the literature. The three themes are; China's aid provision to the region, natural resources, and diplomatic rivalry with Taiwan.

The academic literature on the theme of Chinese aid provision in the South Pacific focuses its analysis on the harm that this aid is causing to the region. It has identified that aid provision has become a significant topic in the South Pacific, due to the sensitive nature of its provision and the problems caused by it, such as issues around dependence. It goes further, arguing that the lack of requirements and conditions attached to aid provided by China has resulted in problems around corruption, instability and lack of coordination. It is argued that Chinese aid has encouraged corruption in South Pacific states, because the lack of oversight of Chinese aid means that Pacific elites are free to use the aid money freely. Saunders states in Chinese Foreign Policy in Asia that China does not impose anti-corruption conditions on its financial aid, as part of its longstanding policy of diplomatic rivalry with Taiwan. ${ }^{97}$ Dobell goes further, arguing that Chinese aid contributed as part of its rivalry with Taiwan has done considerable harm to the region, by making South Pacific politics "more corrupt and more violent". ${ }^{98}$ The work on China's engagement with the South Pacific also attributes an increase in instability within the region to the lack of conditions attached to Chinese financial aid. The move by South Pacific

\footnotetext{
97 Saunders, Philip C., "Chinese Foreign Policy in Asia: Implications for the South Pacific," in AnneMarie Brady (ed.), Looking North, Looking South: China, Taiwan and the South Pacific (London: World Scientific, 2010), p.249

${ }^{98}$ Dobell, Graeme, "China and Taiwan in the South Pacific: Diplomatic Chess Versus Pacific Political Rugby", http://lowyinstitute.cachefly.net/files/pubfiles/Dobell\%2C_China_and_Taiwan_in_the_SP.pdf (accessed May 28, 2012), p.3
} 
states towards China for foreign aid can be attributed to growing frustration at the "big brother" policies of NZ and Australia. It has also been suggested that these states may be playing these traditional powers off against the relative newcomer, China. This has caused South Pacific states to accept larger amounts of financial aid, regardless of their economic situation. This has led to financial instability in several South Pacific states as they struggle to repay the soft loans provided by China. Hanson says that South Pacific states may be accepting soft loans from China despite concerning financial outlooks because they believe that China will write off the debt if requested to. ${ }^{99}$ This theme is expanded on further by Hanson, who focuses on the problem of financial instability by explaining that a key condition China does attach to its aid is the requirement that Chinese companies, labour and materials be used for construction of any projects funded by China. ${ }^{100}$

The secrecy that China attaches to its aid payments has been identified as a major problem to emerge from China's increasing engagement with the region. Because China regards its aid payments as a state secret, it refuses to release details of payments to fellow donor states in the region, and routinely refuses to cooperate with other donor states. ${ }^{101}$ This has resulted in problems around aid duplication as other donors in the region are unaware of what aid China is providing, and to whom. ${ }^{102}$ The academic literature on Chinese engagement with the South Pacific has focused on a major theme of problems caused by China's aid contribution to the region, which can be seen in the secretive nature of aid distribution, corruption caused by this, and the lack of coordination of this aid.

Another major theme covered by the academic literature on Chinese engagement with the South Pacific is the quest for natural resources. China's quest for greater access to natural resources is covered in great detail, which looks at it as one of China's motivations for greater engagement with the region. The South Pacific is rich in key resources, such as fish stocks, natural gas, minerals, timber and oil, but

\footnotetext{
${ }^{99}$ Hanson, Fergus, and Mary Fifita, "Behind China's Secret Aid Programme, Debt Looms," 2011, http://www.abc.net.au/unleashed/55376.html, (accessed May 28, 2012) , p.1 ${ }^{100}$ Hanson, Fergus, "China: Stumbling through the Pacific?" in Anne-Marie Brady (ed.), Looking North, Looking South: China, Taiwan and the South Pacific (Singapore: Word Scientific, 2010), p.96 ${ }^{101}$ Hanson, Fergus, and Mary Fifita, "China in the Pacific: The New Banker in Town", 2011, http://lowyinstitute.cachefly.net/files/pubfiles/Hanson_and_Fifita\%2C_China_in_the_Pacific_web.pdf (accessed May 28, 2012), p.3 102 Hanson, "China", p.97
} 
these resources are expensive to obtain. ${ }^{103}$ This, it is argued, has fuelled greater Chinese engagement with the region, as it seeks to gain access to these resources which are crucial to its modernisation process. It is stated that China has focused its initial engagement with the region, largely involving aid, around improving the region's facilities for accessing these natural resources. ${ }^{104}$ Hanson explains that China has funded projects such as the construction of fish processing plants in Vanuatu, the Cook Islands and PNG, along with a headquarters building for the Tuna Management Commission in Micronesia. 105 The author identifies this as a continuing trend, with China seeking to ensure it has access to the natural resources that exist in the region. Shie argues that China has been heavily involved in developing the South Pacific's natural resource stocks so it can have access to them. ${ }^{106}$ The theme of natural resource access in the literature suggests that it is a significant motivation for Chinese engagement in the region. The focus on natural resources is important, because it highlights a significant aspect of China's engagement with the region. Despite this, economic goods may not necessarily be Beijing's primary motivation for this engagement.

The third key theme on Chinese engagement with the South Pacific is the role that China's diplomatic rivalry with Taiwan plays. The literature identifies China's rivalry with Taiwan as a destabilising factor in the region, as the two fight for official recognition within the UN. They cite several reasons for the destabilisation caused by this rivalry. The main reason for destabilisation caused by the diplomatic rivalry is the quest by China to seek to attract island states to officially recognise it as the one official China. This is because Taiwan needs diplomatic recognition to ensure it has a voice within international organisations such as the UN. 107 This rivalry has caused China to pursue potentially harmful methods of gaining official recognition. Despite the insistence by China that its methods are not causing harm, one of these harmful methods is the use of financial aid without conditions attached, which has caused

\footnotetext{
${ }^{103}$ Hanson, "China", p.87

${ }^{104}$ Hanson, "China", p.88

105 Ibid

${ }^{106}$ Shie, Tamara-Renee, "Rising Chinese Influence in the South Pacific: Beijing's Island Fever", in AnneMarie Brady (ed.), Looking North, Looking South: China, Taiwan and the South Pacific (London: World Scientific, 2010), p.143

${ }^{107}$ Lintner, Bertil, "The South Pacific: China's New Frontier", in Anne-Marie Brady (ed.), Looking North, Looking South: China, Taiwan and the South Pacific (London: World Scientific, 2010), p.20
} 
instability through debt and corruption. Another effect of the rivalry contributing to destabilisation in the region is the link between this rivalry and conflict in the region. The diplomatic rivalry between China and Taiwan has contributed to fuelling existing conflicts in some South Pacific countries. ${ }^{108}$ Anti-Chinese riots have occurred across the South Pacific in places such as Nuku'alofa and the Solomon Islands. ${ }^{109}$ China and Taiwan's willingness to provide aid to these countries has led to incidents of politicians defrauding their country by corruptly funnelling Chinese aid money for their personal use. These conflicts are explored by the literature due to the relationship between China's increasing engagement with the region and the reasons for the conflict. The Chinatown riots in Nuku'alofa were caused by anger towards Chinese migrants, but the literature also argues that there is anger caused by a perceived lack of action by China towards the consequences of illegal migration by Chinese into the region, and local economic friction between Tongan and Chinese business people. 110 The literature has highlighted the negative consequences of China's diplomatic rivalry with Taiwan in the South Pacific, especially between native communities and the immigrant Chinese population.

As highlighted in this overview, the literature on China's engagement with the South Pacific has had both positive and negative consequences within the region. As shown, the region has greatly benefitted from access to financial assistance, assistance to develop natural resources and improved infrastructure. But below the surface, a growing concern over the negative consequences of China's short-term thinking towards achieving its goals in the region has been identified, which has been highlighted by the corruption and lack of coordination of Chinese aid, the lack of benefits brought by Chinese infrastructure projects and the destabilisation caused by China's policies in the region.

\footnotetext{
${ }^{108}$ Lin, Cheng-yi, "The Security Implications of Cross-Strait Competition in the South Pacific from a Taiwanese Perspective", in Anne-Marie Brady (ed.), Looking North, Looking South: China, Taiwan and the South Pacific (London: World Scientific, 2010), p.114

${ }^{109}$ Brady, Anne-Marie, and John Henderson, "New Zealand, the Pacific and China: Challenges Ahead", in Anne-Marie Brady (ed.), Looking North, Lookins South: China, Taiwan and the South Pacific(London: World Scientific, 2010), p.210

110 Brady \& Henderson, "New Zealand, the Pacific and China", p.211
} 
Review

To fully understand the existing literature on China's engagement with the South Pacific, it must be analysed and interpreted to establish the context of the academic analysis to be covered. As highlighted earlier, the main arguments on China's engagement with the South Pacific focus on aid, natural resources and the diplomatic rivalry with Taiwan. To properly analyse the arguments, they must be looked at individually, to enable them to be thoroughly analysed.

The main argument on Chinese aid in the South Pacific is that the lack of "strings" attached to this aid has created problems for island states who accept aid from China. The aim of the literature has been to highlight these problems, and the associated costs caused by them. This argument is significant because it highlights the dangers posed by China's current approach to currying favour in the South Pacific. This is because China's policy of providing financial aid to the South Pacific has led to countries becoming heavily indebted. This claim is important, because an increasing number of media sources in the region are reporting on the financial burden being placed on island states due to these programmes, in a time of economic upheaval. The Tongan government has accepted soft loans from China worth up to twenty-two percent of its GDP, raising concerns about how it will repay these loans. ${ }^{111}$ This example strengthens the argument put forward because it provides statistical evidence of the negative consequences of Chinese engagement with the region. The overall argument put forward by academics, such as Fergus Hanson, that Chinese engagement in the South Pacific has harmed the region is strong, because it uses several different cases as evidence of the consequences of Chinese engagement. In addition to the financial instability highlighted earlier, the academic literature also focuses on the lack of coordination in aid dispersion and the short-term nature of infrastructure projects. It also argues that China's refusal to disclose its aid figures has harmed island states by preventing donors from being able to coordinate aid distribution. China only attends donor meetings in one Pacific Island country Tonga. ${ }^{112}$ This argument is significant, because it provides an important contribution

111 Hanson, "China", p.96

112 Hanson, "China", p.97 
by highlighting the harm that China's official aid policy is causing, and its effects on the ground in the South Pacific.

The second case that has strengthened the argument made by Hanson and others is the problems associated with a short-term focus by China in regards to infrastructure projects. The literature argues that as part of its efforts to counter Taiwan in the South Pacific, China has focused on providing infrastructural aid, often in the form of "prestige" buildings, such as stadiums to island states in the region, while traditional powers are more focused on providing education, training and human resources aid. Hanson provides the example of the swimming complex provided by China to Samoa, which officials have said is so expensive to maintain that even New Zealand would struggle to cover the costs. ${ }^{113}$ This has significantly contributed to the argument put forward by critics of China's financial support, because it highlights a major problem caused by the short term nature of China's aid provision. This problem has been shown to have negatively affected the region. The argument made by critics in some studies of China's provision of aid in the South Pacific has highlighted the negative consequences for the region, which is important to the academic field. This can be seen in the way that authors such as Hanson have used soft loans, aid secrecy and the short-term focus of Chinese aid to highlight problems caused by China in the region.

The conclusions reached and findings made are important for the understanding of the academic debate on Chinese engagement with the South Pacific, so they must also be examined to further highlight the significance to the academic debate. Three main conclusions put forward will be analysed in greater depth to highlight the gap in research on China's use of soft power to compensate for its current policies towards the region.

The first conclusion that requires analysis was put forward by Fergus Hanson in his article, China: Stumbling through the Pacific? In it he concludes that despite some negative consequences arising from China's actions in the region, China's willingness to provide financial support to the region indicates that there are greater opportunities for China if it continues the reforms to its aid provision that it has

${ }^{113}$ Hanson, "China”, p.95 
begun. ${ }^{114}$ This is important, because it also emphasises the importance that China places on economic development, which fuels its engagement with the region. ${ }^{115}$ The conclusion reached by Hanson is significant to the academic field, because the reforms highlighted in his analysis create opportunities for soft power-based approaches. This link between Chinese aid reforms in the South Pacific and soft power opens up space for research into the role of soft power. Hanson argues that there are already signs that China is reforming its aid provision, by making far fewer promises of flashy infrastructure projects than usual. ${ }^{116}$ China has also made tentative steps towards cooperating with other regional powers, such as collaborating with NZ on an infrastructure project in the Cook Islands. ${ }^{117}$ These examples are important, because they reinforce the conclusion that China's aid programmes in the region holds potential benefits if they are reformed correctly. Hanson recommends that China become more transparent in its aid provision and coordinates its efforts with other donors. Because South Pacific values include a preference for consensus rather than majority rule, any shift by China towards a more cooperative method of aid distribution could increase its soft power in the region.

The second major finding on China's engagement with the South Pacific surrounds the nature of China's engagement with the region. There are two main schools of thought concerning the nature of China's engagement with the South Pacific, those who argue that China's engagement with the region is relatively benign in the sense that China is not seeking to dominate the region, and those who believe that China poses a threat by seeking to take advantage of the region by using it for strategic and military influence. These differing conclusions can be attributed to the perspective of the author. Authors from traditional regional powers tend to take a more pessimistic view of China's engagement. This can be seen in the offensive realist approach taken by Windybank, who proposes that China's interest in the region is due to the strategic advantage of atoll states that lie close to the equator, which

\footnotetext{
${ }^{114}$ Hanson, "China", p.102

115 Yang, Jian, "The South Pacific in China's Grand Strategy", in Anne-Marie Brady (ed.), Looking North, Looking South: China, Taiwan and the South Pacific (London: World Scientific, 2010), p.277

116 Ibid

${ }^{117}$ New Zealand Aid Programmeme, "New Zealand and China Collaborate on World First in Development", 2012, http://www.aid.govt.nz/media-and-publications/developmentstories/september-2012/new-zealand-and-china-collaborate-world-fi (accessed January 17, 2013)
} 
provide an ideal location for satellite tracking and spying on nearby US military bases. ${ }^{118}$ This type of conclusion reached by authors from traditional powers is significant, because it can be observed as coming from a different perspective than those who conclude that China's engagement is benign. The perspective of the author is important because it can be suggested to influence the way that they interpret their analysis. This can be seen in the earlier example from Windybank, an Australian academic whose analysis focused on the threat that China poses in the region. This is also true of the literature that concludes that China's engagement in the region is benign, because the majority of authors who argue this are from the region. This can be seen in the conclusion reached by Iati Iati, who concludes that reservations about China's presence are not reflected in the Samoan population, because China's claim of being a friend holds a much more integral place in the Samoan psyche. ${ }^{119}$ This conclusion is important because it shows a distinct difference in interpretation between those authors who are outside of the region and those within. This however is not to say that the literature from within the region does not identify problems arising from China's engagement. Much of the literature highlights concerns about China's aid practices in the conclusions that they reach. Langa'oi highlights the consequences of relying on Chinese aid in the article, Chinese Diplomatic Relations with the Kingdom of Tonga. In this article, it is argued that Tonga's dependence on foreign aid, and its relatively small number of key decision-makers, have combined to fuel China's engagement with Tonga. ${ }^{120}$ It goes on to conclude that China's use of aid for recognition has proved detrimental to Tonga, which has made Tonga dependent on China for aid to support its economy, due to its narrow economic base compared with other South Pacific states.

The third major conclusion reached on China's engagement with the South Pacific is that the region has become a testing ground for China's increasing soft power. The literature has identified China's increasing soft power as becoming a factor in its activities with the South Pacific. The authors argue that this has been influenced by the OC population in the South Pacific, who view China as a benevolent

\footnotetext{
118 Windybank, Susan, "The China Syndrome", Policy, vol. 21, no. 2, 2005, p.3

${ }^{119}$ Iati, Iati, "China and Samoa", in Terence Wesley-Smith and Edgar Porter (ed.), China in Oceania (Oxford: Berghahn Books, 2010), p.160

120 Langa'oi, Palenitina, "China's Diplomatic Relations with the Kingdom of Tonga", in Terence WesleySmith and Edgar Porter (ed.), China in Oceania (Berghahn Books: Oxford, 2010), p.174
} 
and strong power as a result of its response to the recent unrest in some South Pacific countries. ${ }^{121}$ The authors also contend that the US withdrawal of support from the region, such as a pull-out by agencies like USAID and the Peace Corps, as well as diplomatic posts, has harmed the US's soft power in the region which has opened up space for China to fill. ${ }^{122}$ This combination has allowed China to make use of its burgeoning soft power in the region. It concludes that the combination of increasing awareness of Chinese goods and services, Chinese programming, expanding educational exchanges, encouraging the study of Mandarin, and a boost to tourism have made the peoples of the South Pacific more aware of China's presence and this has increased China's soft power in the region. Iati concludes that the Samoan population do not share the reservations towards China of the traditional powers. ${ }^{123}$ This suggests that China's presence in the region has enhanced the soft power that it wields. This may also be due to the emphasis China places on its status as a "developing state". This is significant because it highlights the need for further analysis of how Chinese soft power is affecting its engagement with the South Pacific. It does however identify challenges to China's soft power in the region. Nelson highlights the issue of Chinese migrants being involved in illegal activities in Papua New Guinea, which reflects poorly on China's reputation in the region. ${ }^{124}$ He goes further, arguing that illegal Chinese migration is undermining China's reputation in the region, due to the resentment that Papua New Guineans hold towards Chinese who are perceived to be taking jobs from them. ${ }^{125}$ This suggests that Chinese soft power is being undermined by the activities of its people in the region.

China's activities to date in the South Pacific have been shown to be harmful by the arguments put forward by the authors. From the destructive short-term focus that China displays when providing aid, to the damaging corruption that is fostered by the diplomatic rivalry between China and Taiwan, China's engagement so far has been criticised by the academic literature. Yet the three conclusions reached about Chinese engagement with the South Pacific are significant for any future analysis of

\footnotetext{
${ }^{121}$ To, James Jiann Hua, "Sino-Pacifica: Extra-Territorial Influence and the Overseas Chinese", in AnneMarie Brady (ed.), Looking North, Looking South: China, Taiwan and the South Pacific (London: World Scientific, 2010), p.72

${ }^{122}$ Shie, "Rising Chinese Influence in the South Pacific", p.154

${ }^{123}$ Iati, "China and Samoa", p.160

${ }^{124}$ Nelson, Hank, "Chinese in Papua New Guinea", in Terence Wesley-Smith and Edgar Porter (ed.),

China in Oceania (Oxford: Berghahn Books, 2010), p.114

125 Nelson, "Chinese in Papua New Guinea", p.115
} 
Chinese education programmes in the South Pacific, because they identify that China can play a positive role in the region. This is because the literature examines the nature of China's engagement, the effects of Chinese aid, and the increasing importance of soft power in the South Pacific. These findings have shown a need for further analysis of Chinese soft power in the region, to identify solutions to enabling greater political and economic engagement by China in the South Pacific. 


\section{Chapter Three:}

\section{China-Tonga bilateral relationship}

China's official relations with Tonga can be traced back to the end of the Cold War, when the traditional powers began to withdraw from the South Pacific. China moved in to fill the void left by the US and former Soviet Union, developing formal relationships with several countries within the region. China officially established diplomatic relations with Tonga on November 2, 1998, when Tonga abruptly switched official recognition from Taiwan to China. This has led to the development of significant political, economic and cultural ties between the two countries. The history of China's bilateral relations with Tonga must be examined prior to any analysis of the correlation between bilateral relations and soft power, because the China-Tonga relationship presents a number of unique aspects compared to China's other relationships in the region.

The decision by Tonga to formally establish diplomatic relations with China came as a shock to actors in the region. This is because prior to the switch, Tonga had close ties to the ROC, frequently travelling to Taipei for official visits. ${ }^{126}$ China's pursuit of official recognition from Tonga can be attributed to the diplomatic rivalry between it and Taiwan, for recognition on the international stage. China's objective in this regard is the marginalisation of Taiwan by co-opting those states who have official relations with Taipei. ${ }^{127}$ China's bilateral relationship with Tonga was greatly enhanced by the political ties it developed in the aftermath of its recognition switch. The basis of these political ties has rested on the frequent use of official visits by each state's leaders. This has come to be known as "visit diplomacy", or "smile diplomacy", by officials. China has invited Tongan political leaders on several high profile state visits to China, as part of its drive to win over the island state. These official visits are often accompanied by promises of aid from China, which are a significant attraction

\footnotetext{
${ }^{126}$ Lintner, Bertil, "The South Pacific: China's New Frontier", in Anne-Marie Brady (ed.), Looking North, Looking South: China, Taiwan and the South Pacific, (London: World Scientific, 2010), p.23

${ }^{127}$ Brady, Anne-Marie, and John Henderson, "New Zealand, the Pacific and China: Challenges Ahead", in Anne-Marie Brady (ed.), Looking North, Looking South: China, Taiwan and the South Pacific, (London: World Scientific, 2010), p.194
} 
to small island states like Tonga with weak economies. One significant example of this visit diplomacy is the 1999 visit by Tongan King Tupou IV to Beijing, where the red carpet was rolled out and promises of aid were made by the Chinese government. ${ }^{128}$ The importance placed on visits by Tongan leaders emphasises the significance placed by China on its relationship with Tonga.

Another aspect of China's political ties with Tonga that contributes to the bilateral relationship is defence cooperation between the armed forces of the two countries. The official visits conducted between China and Tonga led to the establishment of cooperation between Tonga's defence force and the Chinese PLA. This defence cooperation was quickly established following the announcement of official diplomatic relations, however it has been fairly limited compared to other Chinese defence cooperation. This is because China has limited its defence cooperation with Tonga to non-combat areas such as logistics, and infrastructure development. ${ }^{129}$ This cooperation includes the provision by China of martial arts training for members of the Tongan military. ${ }^{130}$ China's cooperation with Tonga in the realm of defence has strengthened political ties at multiple levels. This is because in addition to the Tongan and Chinese leadership meeting and cooperating in the field of defence, this cooperation has connected the military leaders of both countries. The PLA has hosted several meetings with the leadership of the Tongan defence force, strengthening ties between the two militaries. Several meetings between PLA and Tongan defence force officials were held following the establishment of diplomatic relations, including a visit to Tonga by two deputies from the PLA in 2000.131 This example highlights the importance placed on defence cooperation as part of the political ties that were formed immediately following the establishment of diplomatic relations in 1998.

China's use of financial aid and infrastructure projects in the South Pacific has proved an effective tool for deepening its bilateral relationship with Tonga. China has adopted a comprehensive approach to its economic engagement with Tonga, one that

\footnotetext{
128 Lintner, "The South Pacific", p.23

${ }^{129}$ Hanson, Fergus, "China: Stumbling through the Pacific?", in Anne-Marie Brady (ed.), Looking North, Looking South: China, Taiwan and the South Pacific ( Singapore: Word Scientific, 2010), p.92

130 Lintner, "The South Pacific", p.24

131 Lintner, "The South Pacific", p.23
} 
has led to dependence by Tonga on China. To highlight this relationship and its effect on the bilateral relationship, China's use of soft loans, its provision of infrastructure projects, and its trade relationship with Tonga will be examined to highlight the evolution of the China-Tonga relationship.

Soft loans have played a significant role in Chinese foreign policy since its opening-up process began in the 1970s. Soft loans are a type of loan offered by countries and international organisations that feature low interest rates, repayment holidays and flexible terms. ${ }^{132}$ China's use of soft loans in the wider South Pacific region has become particularly prevalent. Hanson shows that Chinese aid reached a high of \$US 153 million in 2008. ${ }^{133}$ This trend is particularly evident in Tonga, where the government has become particularly dependent on Chinese soft loans. Tonga's government has accepted a number of soft loans from China, including one totalling \$US 45 million in 2007/2008.134 China's willingness to lend money without the usual strings attached, such as good governance conditions, and Tonga's willingness to accept these loans has led to the dependent relationship that now exists. This has created significant problems for Tonga in its ability to repay the loans when they come due, because of the one-sided trade relationship that exists between the two countries, which will be examined later. This dependent relationship that exists between Tonga and China has led to Tonga incurring large debts, such as reconstruction aid for Nuku'alofa, which it will struggle to pay off. Hanson and Fifita explain that Tonga has borrowed the equivalent of one-third of its annual GDP from China. ${ }^{135}$ There is also increasing evidence to show that China is not prepared to wipe these debts out should Tonga prove unable to repay them. Hanson and Fifita have noted that South Pacific countries have requested that China forgive their loan debts, only to be rebuffed by the Asian superpower. ${ }^{136}$ China's relationship with Tonga has created a dependence on Chinese aid, and Tonga is harmed by the increasing debt it

\footnotetext{
132 MacMillan Dictionary, "Soft Loan - Definition", 2012, http://www.macmillandictionary.com/dictionary/british/soft-loan (accessed September 24, 2012) 133 Hanson, Fergus, "China: Stumbling through the Pacific?", in Anne-Marie Brady (ed.), Looking North, Looking South: China, Taiwan and the South Pacific, ( Singapore: Word Scientific, 2010), p.84

134 Chapman, Kate, "Chinese Loan Likely to Be Hard Going for Tonga", 2011, http://www.stuff.co.nz/world/south-pacific/5281034/Chinese-loan-likely-to-be-hard-going-forTonga (accessed 24 September 2012) 135 Hanson, Fergus, and Mary Fifita, "Behind China's Secret Aid Programme, Debt Looms", 2011, http://www.abc.net.au/unleashed/55376.html (accessed 24 September 2012), p.1 136 Hanson \& Fifita, Behind China's Secret Aid Programme", p.2
} 
finds itself in. The benefits that China receives from this relationship will be examined in greater detail in later sections.

Infrastructure has become a significant area in which China has enhanced its bilateral relationship with Tonga. China has become a significant contributor of infrastructure such as roads, hospital buildings, and barracks, to the South Pacific. The use of infrastructure projects by China has stemmed from its increasing commitment to development assistance for countries in the region that have officially recognised it. The construction of infrastructure by China in the South Pacific has focused on projects with large visibility benefits, such as grandiose buildings, roads and harbour facilities. This has had both positive and negative impacts on the region, and Tonga in particular. Tonga's bilateral relationship has seen a large scale increase in infrastructure development by China, such as refurbishment of airports, roads and convention centres. ${ }^{137}$ China has also played a role in strengthening its relations with Tonga by rebuilding the shopping districts of Nuku'alofa destroyed in the antiChinese riots that occurred in 2006. ${ }^{138}$ This type of infrastructure development by China has had a positive effect on bilateral relations, as it makes Tongans more aware of China's presence and the role it plays in their country. In addition to the positive outcomes from China's provision of infrastructure to the region, the need for it to be visible in the South Pacific has led to the prioritisation of "visible" projects. This has meant that China has prioritised projects that are highly visible to the peoples of the country it is being built in. This is evident in countries like Tonga, where China built an extension to the royal palace in the Tongan capital, Nuku'alofa. ${ }^{139}$ This trend is particularly true in Tonga, where recent history highlights China's willingness to provide infrastructure to the country. This has led to China building a number of projects that are costly to maintain or not needed by the communities they are built for. One example of this is a grant provided by China to build a convention centre in

\footnotetext{
${ }^{137}$ Hanson, Fergus, \& Mary Fifita, "China in the Pacific: The New Banker in Town", 2011, http://lowyinstitute.cachefly.net/files/pubfiles/Hanson_and_Fifita\%2C_China_in_the_Pacific_web.pdf (accessed 25 September 2012), pp.22-24

${ }^{138}$ Craymer, Lucy, "China Seeks to Star in South Pacific", 2012,

http://online.wsj.com/article/SB10001424052702303815404577334522576045372.html (accessed September 25, 2012)

139 Grubel, James, "Pacific Micro-Nations Cash in on US-China Aid Rivalry", Reuters, September 42012
} 
the country. ${ }^{140}$ Tonga has benefited significantly from its bilateral relationship with China, in the form of infrastructure provision, but China's priorities have resulted in unnecessary and costly projects that have made it difficult for Tonga to maintain.

The bilateral relationship between China and Tonga has progressed to the point where the two countries have expanded their relationship into the area of trade. This is an important aspect of bilateral relations, because it highlights the manner in which China is able to take advantage of Tonga due to its weak economic base. This is because Tonga does not have the developed tourism industry or large natural resource stocks of its neighbours, which makes it reliant on China. The trade relationship that exists between China and Tonga is very one-sided, based on trade statistics and anecdotal evidence. Trade between China and Tonga provides economic benefits to both countries, as China has access to a market for its goods, and Tonga has access to cheap Chinese imports. This is evident in statistics released by ANZ Bank, which states that in 2009, Tonga imported 5.9 percent of its goods from China, while for the same year its exports to China were a mere 0.9 percent of its total exports. ${ }^{141}$ China is also keen to take advantage of the natural resources that are available in Tonga. The South Pacific is home to large fish stocks, and China is seeking to take advantage of this to feed its growing population. To accomplish this, China has bought licences to fish within the EEZs of a number of South Pacific states. This is also true in Tonga, where not only has China purchased a licence to fish in the Tongan EEZ; it has also invested in infrastructure upgrades to ensure it is able to process the fish that it catches. ${ }^{142}$ This growing cooperation between China and Tonga in the area of fishing has led to increasing criticism of the damaging practices being employed by Chinese companies to catch fish. The Pacific Islands Tuna Industry Association has stated that the influx of Chinese fishing fleets is putting Tongan fishermen out of business, as more and more Chinese fishing boats are operating within Tonga's EEZ. ${ }^{143}$ The developing trade relationship has allowed Tonga to gain access to cheap

140 China Daily, "Tonga Seeks \$60m Loan from China to Buy Back Assets", 2006, http://www.chinadaily.com.cn/bizchina/2006-04/27/content_585992.htm (accessed 27 September 2012)

${ }^{141}$ ANZ, Economics \& Global Markets Research: Pacific Quarterly, (accessed 27 September 2012), p.3 142 Davis, Lloyd Spencer, "Not All Tuna Are Created Equal", 2012, http://www.taimionline.com/articles/6654 (accessed September 28, 2012) 143 Real, Natalia, "Chinese Subsidies Are Damaging the Pacific Islands Tuna Sector", 2012, http://fis.com/fis/worldnews/worldnews.asp?monthyear=\&day=17\&id=54686\&l=e\&special=0\&ndb $=0($ accessed September 28, 2012) 
products, but it has also allowed China to take advantage of Tonga's natural resources, often to the detriment of Tongan citizens.

The evolving bilateral relationship between China and Tonga has seen social relations between the two countries develop during the period since Tonga officially recognised China. Cultural relations have been recognised by China as a significant aspect of its foreign relations, and this significance can be observed in its official relations with Tonga. To highlight the importance placed by China on its social relations with Tonga, the use of media and culture will be examined to show the evolution of the bilateral relationship.

China has taken full advantage of its media to enhance the social ties between it and Tonga. This is because China broadcasts CCTV-9 into the South Pacific, a channel interpreted as China's foreign propaganda channel. ${ }^{144}$ By broadcasting its official propaganda channel into the region, China is able to broadcast its message straight into the homes of South Pacific peoples, giving it a direct form of communication with the people of the region, often in competition with NZ and Australian media who also broadcast into the region. This trend is also evident in Tonga, where China has used media to spread its message directly to the citizens of the country. As with the wider region, CCTV-9 is broadcast into Tonga. This has played a vital role in bolstering bilateral relations between the two countries, in large part because it educates Tongan audiences to China and its activities abroad. Crocombe argues that CCTV-9 educates Tongans to a country that they know little about, but need to understand better. ${ }^{145}$ Despite this, the attempts by China to use its media to educate Tongans about it and to enhance social relations have been limited due to the dull nature of programmes broadcast by CCTV-9. ${ }^{146}$ This has reduced the effectiveness of Chinese media in enhancing the social ties between it and Tonga, because it is used too much to propagandise. This use of CCTV-9 in Tonga has allowed China to educate the people about its motives; however, Ron Crocombe states that

\footnotetext{
${ }^{144}$ Brady \& Henderson, "NZ, the Pacific and China", p.213

${ }^{145}$ Crocombe, Ron, "The Software of China-Pacific Island Relations", in Anne-Marie Brady (ed.), Looking North, Looking South: China, Taiwan, and the South Pacific, ( London: World Scientific, 2010), p.37 146 Ibid
} 
the effectiveness of this message has been diluted by the perception that the shows broadcast by CCTV-9 are dull and trying to spread the Chinese government's message.

China has used its powerful historical and cultural background to help expose the peoples of the South Pacific to its society. This has involved sending cultural groups to South Pacific countries to perform, and brought exhibitions to the South Pacific that showcase Chinese culture. China has placed considerable importance on its culture and the role it plays in enhancing relations between China and the region. This is particularly true for Tonga, which has benefitted from China's efforts to put its culture on display in the country. One such way in which China has put its culture on display in Tonga is the use of cultural delegations in schools. This allows Tongan students to be directly exposed to Chinese culture in a relaxed way that educates them about China without the obvious presence of official state action. One example of this is the visit to Tongan schools of a Chinese Wushu delegation, which visited schools in the country to show off dance and fight scenes that are part of the art of Wushu, among other cultural events. ${ }^{147}$ The students were reported to be very interested in the exhibition, which highlights the role that culture is playing in China's efforts to increase understanding by Tongans of its cultural heritage. ${ }^{148}$ Programmes like these being provided by China to Tonga highlight the strengthening social relations between the two countries, which are part of an ever-increasing bilateral relationship in the region.

The bilateral relationship between China and Tonga started from a relatively small position to become a wide-ranging and significant relationship. This relationship has had far-reaching consequences for Tonga, from the elite level to the local level. Whether it is the provision of significant amounts of financial aid by China, or the ability of Tongans to access cheap Chinese products, this bilateral relationship has touched Tongans at all levels of society. This relationship is still evolving, with education set to become a major area of focus for China in the coming years. The role that education is playing in educating Tongans about China will be analysed to assess the importance of it to the discourse of Chinese diplomacy.

147 Finau, Sitiveni, "Chinese Cultural Show Popular with Children", News Today, 28 May 2010 148 Ibid 


\section{Chapter Four:}

\section{Chinese soft power in Tonga: the role of education in bilateral}

\section{relations}

The bilateral relationship between China and Tonga represents a new phase in China's foreign relations. Tonga represents a unique case in the expansion of Chinese influence within the South Pacific, particularly due to the state of the economy and the role that the overseas Chinese community plays in Tongan society. The ChinaTonga relationship stands as a case study in need of deeper analysis, as it can provide insights into China's role and position in economically dependent and socially divided societies like Tonga. The use of soft power by China in Tonga is an important aspect of this relationship, as China seeks to soften its image in the country as it deepens its relationship and becomes more visible. To properly understand the role that soft power is playing, this section will seek to examine a number of themes. Prior to any analysis of China's provision of scholarships in Tonga, the bilateral relationship will be analysed to examine the areas that make it a unique case within the South Pacific. Following this, China's policies in the wider region will be analysed to identify China's priorities and objectives in the wider South Pacific. The following section will analyse China's provision of scholarships in Tonga as a form of soft power, to identify the ways that China is seeking to improve its image. The expansion of China's relationship will also be analysed, to enable this to be compared to the corresponding soft power initiatives. Finally, China's relationship with Tonga will be compared to the bilateral relationship between China and South Africa, to highlight and examine the unique nature of the Chinese relationship with the South Pacific, compared to its established relations in Africa. This comparison will allow China's bilateral relationship to be tested against another relationship, to examine whether it is a unique relationship, or whether it follows the pattern of other Chinese relationships. 


\subsection{China-Tonga bilateral relations: a unique case}

The case of China's relations with Tonga is particularly unique to the field of Chinese foreign relations. This is due to a number of external factors that have influenced the nature of the relationship. To better understand the nature of the China-Tonga relationship and its uniqueness compared to other South Pacific states who maintain relations with China, this section will examine the aspects of the ChinaTonga relationship that differ from the other relationships that China has in the region, analyse how they differ from those seen in other South Pacific states, and evaluate how these factors make the China-Tonga relationship unique to the region.

\section{Economic Dependence}

The economy is one area where the unique nature of China's relationship with Tonga is evident. Tonga has long been reliant on external sources for economic growth, whether it is in the form of remittances from overseas communities or the tourism industry. This reliance on external factors has resulted in the Tongan economy becoming heavily dependent on foreign actors for its economic growth. This weakness has been heavily exploited by large powers in taking advantage of Tonga for their own goals and objectives. To better understand this before analysing China's role, the nature of the Tongan economy must be examined. The Tongan economy is heavily reliant on external factors, such as the industries it relies on, the state of Tongan exports, and the nature of foreign aid provision.

Tonga's major industries all share a common trait; they are vulnerable to external factors. The three largest industries in Tonga are agriculture, tourism and fisheries. These three industries all rely heavily on overseas markets for their prosperity. In the case of agriculture, it accounts for almost two-thirds of Tonga's total exports. ${ }^{149}$ Tonga's agricultural sector is particularly reliant on overseas markets, due to the largest exports going to markets in Japan, Korea and New Zealand. Tonga's major exports are animal products and vegetable products such as squash,

149 Tonga Chamber of Commerce and Industry. "Facts About Tonga", 2010, http://www.tongachamber.org/tonga-factsheet (accessed October 19, 2012) 
root plants and coconuts. ${ }^{150}$ The significant proportion of Tongan exports that come from agriculture means that the Tongan economy is particularly vulnerable to economic downturns and price decreases in its exports. ${ }^{151}$ In a speech given by the Tongan Prime Minister, he states that the economy has been significantly affected by the Global Financial Crisis, which has resulted in less growth than expected in the agricultural sector. ${ }^{152}$ This combination of the GFC and the large proportion of export revenue Tonga earns from agriculture has been shown to create significant vulnerability in Tonga's economy, which creates a need for economic growth. This can be suggested to have contributed to the dependence on foreign assistance that the Tongan economy experiences.

The second major industry that is vulnerable to external factors is tourism, which is heavily dependent on foreign visitors to the country, yet is significantly underdeveloped compared to other South Pacific states. This is because tourism is influenced by a number of conditions which are often outside of the control of the Tongan government. One condition outside of their control is the Global Financial Crisis, which has been discussed earlier. The GFC has caused tourist numbers to fall across the world, as economic conditions influence the amount of money people have to spend. This has resulted in the shrinking of the tourism industries of a number of countries. The evidence suggests that the GFC has affected the number of tourists visiting Tonga, making the economy weaker as one of its largest industries struggles. Since the start of the GFC the tourism industry went from 46,000 air visitors in 2007 to 45,000 in $2010 .{ }^{153}$ This suggests that Tonga's tourism industry has shrunk because of the GFC, which highlights the vulnerability of the Tongan economy to external factors such as the GFC.

The third major industry in Tonga that is vulnerable to external factors is the fisheries industry. Tonga's EEZ is comparatively large compared to the rest of the world, and possesses large stocks of tuna and other fish. This makes it an important

\footnotetext{
150 Finau, Ata'ata, “Annual Foreign Trade Report for 2010" (Nuku'alofa: Statistics Department, 2010), p.3

151 Tu'ivakano, Siale'ataonga, "Growing Our Economy: A Collective Effort", (speech, Nuku'alofa, March 7 2012), Ministry of Information and Communications, http://www.pmo.gov.to/news-today/pressreleases/3440-prime-minister-lord-tuivakano-opening-address-at-the-economic-dialogue-2012qgrowing-our-economy-a-collective-effortq 152 Ibid 153 Tonga Department of Statistics, "Air Visitors", 2012, http://www.spc.int/prism/tonga/index.php/tourism-statistics/81-air-visitors (accessed October 19, 2012)
} 
part of the Tongan economy, but also vulnerable to external factors. This industry has become particularly significant to outside actors, particularly emerging economies looking to feed their expanding populations. This has led to increasing investment in Tonga's fishing industry, as these states seek to open up greater access. Despite this, Tonga's fishing industry is shrinking as a percentage of the country's GDP.

Government statistics state that the contribution of the fisheries industry to Tonga's economy as a percentage of GDP has fallen by 23 percent between 2005 and $2011 .{ }^{154}$ This can be attributed to several external factors, which have all contributed to the fall in contribution of fisheries as a major industry. One such external factor is the problem of illegal fishing that occurs within Tonga's EEZ. This has created problems around the health of Tongan fisheries, as illegal fishing depletes fish stocks and is not subject to accountability. One such example of this is Tonga's forced closure of a sea cucumber fishery in 2012, due to depletion from illegal fishing. ${ }^{155}$ Illegal fishing is often undertaken by foreign fishing vessels that are often able to flout laws around fishing in the region, due to the comparatively large size of its maritime economic zone. The FFA highlights the case of a Taiwanese fishing vessel that was prosecuted for illegally fishing in Tongan waters. ${ }^{156}$ The two examples provided highlight the problems facing Tonga's fishing industry, due to external factors such as illegal fishing by foreign vessels.

This reliance on agriculture and fisheries means that Tonga is reliant on exporting its products to provide income for its economy. This makes it reliant on external factors such as the trade policies of its major trading partners, and the state of the global economy. The Tongan economy is reliant on four major countries as destinations for its exports; these countries are: Australia, Japan, US, and NZ. As a proportion of total exports, Tonga is reliant on these countries for 94 percent of its exports. Despite this, Tonga is still facing a negative balance of trade with all of its major trading partners. This is because it is heavily reliant on these countries for many of the goods that are sold in Tonga. In the first quarter of 2012 Tonga exported $\$ 566,528$ worth of goods to New Zealand, its fourth-largest export trading partner,

\footnotetext{
154 Tonga Department of Statistics, "GDP Bulletin", (Nuku'alofa: Statistics Department, 2012), p.5 155 Radio NZ, "Tonga Fisheries Imposes Three Year Ban on Sea Cucumbers", 2012, http://www.rnzi.com/pages/news.php?op=read\&id=68459 (accessed 20 October 2012) 156 Ride, Anouk, "FFA Members Support Tonga's Bid to List Vessel for Illegal Fishing", 2008, http://www.ffa.int/node/68 (accessed October 20, 2012)
} 
yet it imported $\$ 21,916,655$ worth of goods from NZ. ${ }^{157}$ This example highlights the reliance that Tonga has on its external trading partners, due to its geographic isolation. Tonga has faced an increasing negative balance of trade since 1997, where it was just below $\$ 100$ million. ${ }^{158}$ This negative balance of trade increased between 1997 and 2011, where it grew to $\$ 305$ million. ${ }^{159}$ This example highlights the reliance of the Tongan economy on external factors such as foreign imports and exports for its growth. It also shows that the export sector is unable to cover the cost of importing goods for sale, which creates further reliance on external factors. This will be examined and greater detail in the following section.

The relative weakness of Tongan exports has created a situation where Tonga has high comparative debt, making it significantly reliant on foreign aid to survive. ${ }^{160}$ The CIA Factbook on Tonga identifies that it is dependent on external aid and remittances to reduce its deficit. This aid comes from a variety of sources, with a wide range of motives, but provides a significant proportion of Tonga's annual income. The CIA estimates Tonga's annual GDP to be at $\$ 439$ million, of which foreign aid makes up a significant proportion. ${ }^{161}$ This has made the country reliant on relationships with existing powers such as Australia and NZ, as well as rising powers such as China. This reliance on foreign aid as part of its annual budget is highlighted by the Tongan statistics department, which states that between 2002 and 2005 Tonga received $\mathrm{T} \$ 24,031,000$ in budgetary aid. In addition to this, NZAID has provided Tonga with NZ\$20 million in the 2011/2012 financial year. ${ }^{162}$ AUSaid has also allocated AUS\$33.8 million for the 2012/2013 financial year. ${ }^{163}$ These amounts highlight the significant role that foreign aid plays in the Tongan economy, as the figures make up a significant proportion of annual GDP. The problems posed by this aid in regards to Tonga's deficit have been highlighted in the media. The NZ Herald

\footnotetext{
157 Finau, Ata'ata, Quarterly Foreign Trade Report, (Nuku'alofa: Statistics Department, 2012), p.7 158 Finau, Ata'ata, Annual Foreign Trade Report for 2010, (Nuku'alofa: Statistics Department, 2010), p.viii

159 Tonga Statistics Department, "International Trade Summary", 2012, http://www.spc.int/prism/tonga/index.php/economic/merchandise-trade (accessed November 1, 2012)

${ }^{160}$ Central Intelligence Agency, "Tonga", 2012, https://www.cia.gov/library/publications/the-worldfactbook/geos/tn.html (accessed November 12012 )

161 Ibid

162 New Zealand Aid Programmeme, "Aid Allocations 2011/12", 2011, http://www.aid.govt.nz/aboutaid-programmeme/aid-statistics/aid-allocations-20112012 (accessed November 12012 ) 163 AusAID, "Tonga", 2012, http://www.ausaid.gov.au/countries/pacific/tonga/Pages/home.aspx (accessed November 12012 )
} 
reported on the measures Tonga is having to take to repay a loan from China. These measures included closing its high commission in Wellington. ${ }^{164}$ The examples provided highlight the dependence that Tonga has on external actors, which has been exacerbated by the foreign aid provided to it.

The three areas examined here have highlighted the significant problems facing the Tongan economy. These problems are unique, in that Tonga is subject to vulnerability in all of its major industries, which is not often seen. The reliance that Tonga has on external actors for its exports, imports and foreign aid are all unique compared to other states in the region. The following section will examine China's role in these industries, compared to its role in other South Pacific economies.

The vulnerabilities identified in the previous section have been taken advantage of by China, as it seeks to further integrate itself into Tongan society as part of its bilateral relationship. This has led to Tonga becoming heavily reliant on China for its economic growth, as its largest industries become squeezed due to external factors. To highlight this, the section will examine China's role in Tongan industries, imports and exports, and aid dependence. This will show how China is becoming involved in Tonga's economy in a way that is not usually seen in other parts of the South Pacific.

Tonga's agriculture industry has been shown to be a significant player in the Tongan economy, as it accounts for a large proportion of the country's GDP. China's growing engagement with the country has influenced the agriculture industry, due to its behaviour in regards to imports and exports. Tonga has become a destination for some of the cheap goods produced in China, accounting for a proportion of Tonga's annual imports. This is highlighted in statistics released by ANZ, which state that China's exports to Tonga have been steadily increasing, from 2.2 percent of its total exports in 2000 to 5.9 percent in 2009.165 This increase suggests that Tonga is becoming a desirable market for China's exports. An alternative explanation for the increase is that the increase in imports is due to loan-related import requirements. Despite this, Tonga has been granted little access to Chinese markets for its own exports. This is also highlighted by the ANZ in their annual Pacific Quarterly, which

${ }^{164}$ Chapman, Kate, "Chinese Loan Likely to Be Hard Going for Tonga"

165 Gruenwald, Paul, Vincent Conti, Bora Bedamu Jr, Shu Zhen Pay, and Daniel Wilson, Pacific Quarterly, (Sydney: ANZ, 2011), p.3 
reports that during the same period exports from Tonga to China grew slightly from zero percent in 2000 to 0.4 percent in 2009.166 This is further evidenced in the export statistics released by the Tongan government, which state that in 2010 China was ranked ninth among countries of destination for Tonga's exports, with a total of $\$ 81,271$ in exports from Tonga. ${ }^{167}$ This is significant to the vulnerability of the Tongan economy because it highlights the lack of reciprocal trade in the China-Tonga economic relationship.

China's role in the Tongan fisheries industry is also causing harm to the wider economy. This is due to the presence of Chinese fishing companies and the subsidies provided to these companies to fish in Tonga's EEZ. This has harmed the Tongan fishing industry, as local fishers struggle to compete with the Chinese fleet that is backed by these subsidies. PITIA chairman Charles Hufflett explains that China provides fuel subsidies to any Chinese fishing vessels that spend more than $\$$ US 700 on fuel per ton of fish caught. ${ }^{168}$. PITIA also states that these subsidies are preventing Tongan fishermen from entering the industry, due to the unequal nature of the competition. ${ }^{169}$ These examples highlight the barriers that the Tongan fishing industry faces due to Chinese involvement. The inability of Tongan fishing boats to compete with Chinese subsidies is important, because it shows how vulnerable the industry is to external factors such as subsidies to foreign fishing vessels they compete with.

China's increasing involvement in Tonga's construction industry has occurred in partnership with the increase in Chinese soft loans to the country. This is due to conditions attached to these loans which prevent Tongan construction firms from winning contracts for infrastructure projects that are funded with Chinese loans. One such example of this is the reconstruction of the Nuku'alofa CBD following the 2006 riots, which was funded by China. As part of the soft loans provided, the China Civil Engineering Construction Corporation (CCECC) was contracted to complete the reconstruction. ${ }^{170}$ This example highlights the problems posed by China's soft loans

\footnotetext{
166 Ibid

167 Finau, Annual Foreign Trade Report 2010, p.42

168 Real, Natalia, "Chinese Subsidies Are Damaging the Pacific Islands Tuna Sector"

169 Ibid

170 Ministry of Information and Communications, "Queen Nanasipau'u Honored Handover Ceremony of Nuku'alofa CBD Phase 1 Reconstruction Project", 2012, http://www.pmo.gov.to/news-
} 
in Tonga, and the harm it causes the Tongan economy. It also shows how susceptible Tonga's construction industry is to external factors such as Chinese soft loans.

China has an active role in the Tongan import markets, as it seeks another destination for its cheap goods. This has impacted on Tonga's dependence on external actors, as China takes advantage of the country as a destination for its goods without reciprocating. This is significant because it reinforces the dependent nature of Tonga's relationship with China, as it relies on it for cheap goods but does not gain any reciprocal benefit by exporting goods to China. This is evident in the statistics relating to China's exports to Tonga compared to its imports from the country. Despite China benefitting from the Tongan market, Tonga has failed to get its exports into the Chinese market. This highlights the way that China is making Tonga dependent on it for economic growth and deficit reduction, due to the unconditional nature of their trade relationship.

The use of financial aid as part of its bilateral relationship with Tonga has significantly contributed to Tonga's dependence on China. This is due in large part to the narrow base that Tonga's economy is formed on, which was examined in previous sections. This narrow base has meant that Tonga is reliant on external sources of capital such as financial aid and remittances from overseas Tongan communities. This has allowed China to become a significant source of financial aid to Tonga, due to its large financial wealth and lack of conditions attached to the aid that it provides. China has provided Tonga with significant amounts of aid, often in the form of soft loans. These soft loans come with conditions that are far more relaxed than traditional loans. This has meant that Tonga has accrued significant levels of debt through these Chinese soft loans. In the financial year 2007/2008 Tonga borrowed \$NZ 54 million in soft loans from China. ${ }^{171}$ Cases such as this have created significant issues for Tonga around its economic deficit. This is highlighted in the same article, which states that Tonga is facing a \$NZ 20 million deficit, and is having to close some of its high commissions to cut costs. ${ }^{172}$ Of this deficit, debt to China plays a significant part. A recent news article states that Tonga's debt to China makes up 23 percent of

today/royalty/3987-queen-nanasipauu-honored-handover-ceremony-of-nukualofa-cbd-phase-1reconstruction-project (accessed October 21, 2012)

171 Chapman, "Chinese loan likely to be hard going for Tonga"

172 Ibid 
its GDP. ${ }^{173}$ The lack of conditions and freedom with which China provides these soft loans has been attributed with the rise in Tongan debt, as Tonga often accepts these loans in the belief that China will write them off should they be unable to repay it. ${ }^{174}$ This belief is based on past Chinese debt forgiveness, however China has recently turned down two requests for debt forgiveness. ${ }^{175}$ This example highlights the dependence that Tonga has on China for its economic growth and deficit reduction, due to the reliance it has on Chinese aid.

China's involvement in Tonga's three main industries, its unequal role as a trading partner, and its provision of financial aid has been shown in this section to have contributed to its vulnerability to external factors, which is a unique aspect of the relationship not often seen in China's other bilateral relationships in the region.

\section{Ethnic Tensions}

Tonga has experienced increasing issues due to the changing ethnic face of its society, due in large part to unchecked illegal Chinese immigration into the country. This has created issues that are not common across the rest of the region. The increasing ethnic tensions in Tonga can be attributed to a number of variables that exist in the country. To properly understand how ethnic tensions are a unique aspect of the China-Tonga relationship, this section will analyse the Chinese immigration into Tonga, the role of Chinese commerce in Tongan society, and the Nuku'alofa riots to highlight how these variables have influence the official relationship.

The rapid migration of Chinese peoples into the South Pacific has created issues around criminal activity and unchecked immigration from China. This is particularly true of Tonga, which has seen considerable ethnic change over the past thirty years, which has led to rising ethnic tension. This can be attributed to unchecked immigration policies initiated by the government to draw revenue. Tonga has a small Chinese population, making up 1.1 percent of the Tongan population at the 2006 census. ${ }^{176}$ Legal Chinese immigration into Tonga can be attributed to a

\footnotetext{
173 Young, Audrey, "China's Aid to the Pacific Tops \$800m", NZ Herald, April 112011

174 Ibid

175 Ibid

176 Tonga Department of Statistics, "Tonga 2006 Census of Population and Housing, Volume 2:

Analytical Report", (Nuku'alofa: Statistics Department, 2008), p.34
} 
number of schemes initiated by the government to generate income and expand the labour pool for its economy. These "cash-for-passport" schemes, established in 1983, are estimated to be worth billions; due to Chinese citizens' desire for a second passport should things deteriorate in China. ${ }^{177}$ The South China Morning Post reported that Tonga sought to sell seven thousand Tongan passports for up to $\$ 20,000$ in 1996, prior to Hong Kong's transfer of sovereignty. 178 This is significant to the China-Tonga bilateral relationship, because it brings associated costs to the country. Such costs include the prospect of illegal activities, due to the lack of oversight associated with the passport sales. This fear was underlined by the Independent Commission Against Corruption, which states that those involved in the purchase of Tongan passports may be tempted to run illegal enterprises. ${ }^{179}$ This has become a significant problem in Tonga, as Chinese immigrants gain citizenship legally then establish criminal enterprises, often involving prostitution, gambling or drugs. This can be seen in news reports from the country, which record increased cases of people trafficking and prostitution, among other crimes committed by Chinese nationals. A Chinese woman was found guilty of trafficking Chinese women into Tonga, trading in prostitution, and operating a brothel. ${ }^{180}$ This example is significant, because it highlights a growing problem in the China-Tonga bilateral relationship that is relatively unique to the country. This has occurred in other countries in the region, but not to the extent that it is occurring in Tonga.

Another aspect of the China-Tonga bilateral relationship that has created and enhanced ethnic tensions in the country is the role of Chinese immigrants in commerce in Tonga. This is due to the differences in behaviour and attitudes held by Chinese and Tongan business people. The policies initiated by the Tongan government of unrestricted immigration, particularly of Chinese peoples, have led to a change in the way that business is conducted in Tongan society. This change has caused tension between the native Tongans and the Chinese immigrants, due to the perception that these immigrants are taking jobs and business away from the Tongan community. This is significant, because it highlights the instability that the increasing

\footnotetext{
177 Schloss, Glenn, "Passport Trade Worth Billions", South China Morning Post, August 19, 1996 178 Ibid

179 Ibid 180 Matangi Tonga Online, "Woman Guilty of Trafficking and Enslaving Girls for Prostitution", Matangi Tonga, April 26, 2011
} 
relationship between China and Tonga is creating. This increasing instability can be attributed to fears that the rising Chinese presence is destroying the "Tongan way of life", as this changing ethnic ratio alters the way that commerce is exercised. Chinese have rapidly taken over the local grocery stores. ${ }^{181}$ Where there were no foreignowned stores twenty years ago, Chinese immigrants have expanded since 1987 to own seventy percent of grocery stores in the country. ${ }^{182}$ This example highlights the changing demographics in Tonga that are fuelling the ethnic tensions. The result of these changes is acts of violence such as the case of a Chinese shop under construction, which was torn down by local Tongan youths. ${ }^{183}$ This example highlights how the growing China-Tonga relationship has fuelled ethnic tensions within the country, as more Chinese enter the country and upset the traditional cultural balance.

This combination of unregulated Chinese immigration into Tonga, and its corresponding effect on Tongan commerce, has led to flashpoint incidents occurring as the native Tongan citizens' vent their anger in violent incidents. This is a fairly unique aspect of the relationship, as China has not faced such riots in the majority of other South Pacific states. The most significant incident to have occurred as a result of the increasing China-Tonga relationship has been the 2006 Nuku'alofa riots. It can be suggested that one of the factors that led to the riots was the increase in Chinese immigrants, and the consequences of this increased immigration. This is significant, because it highlights the problems associated with the China-Tonga relationship at that time. China was focusing much of its attention on the political elites within Tonga, which ignored problems faced by Tongan citizens as a result of the increasing relationship, such as tensions from new Chinese immigrants pushing in on Tongan grocery stores. This is evident in the Chinese presence in local shops, which have threatened the livelihoods of local Tongans. Factors like this led to an outbreak of violence against Chinese-owned shops and other property in the capital Nuku'alofa in 2006. The riots led to the central business district of Nuku'alofa being largely destroyed and Chinese migrants being evacuated due to the attacks on their businesses. China Daily reported on efforts by the Chinese government to evacuate its

\footnotetext{
${ }^{181}$ Lintner, Bertil, "The Sinicizing of the South Pacific", Asia Times, April 182007 182 Ibid ${ }^{183}$ Radio Australia, "Reform movement wants end to issue of permits for Chinese migrants", $B B C$, September 212000
} 
citizens from the country by using privately chartered aircraft. ${ }^{184}$ This example highlights the instability that focusing on the political elite level of the China-Tonga relationship has had on Tonga, and why China had to move its focus towards the citizens of Tonga, as part of its quest to enhance the political and economic relationship.

The China-Tonga bilateral relationship has featured a number of factors that are not commonly found in China's other relationships within the region. Two examples of this are economic dependence and ethnic tensions. The case of the 2006 Nuku'alofa riots is also an example of what can happen when these factors combine with a lack of focus on the citizens of a country, to create anger among the Tongan people about China's increasing presence in the country. The following section will examine China's policies in the wider South Pacific, and examine which can be considered hard power and which can be considered soft power. These policies will then be evaluated to highlight the relationship between the two.

184 Jize, Qin, "Chinese Citizens Evacuated in Tonga", China Daily, November 232006 


\subsection{Chinese policies across the South Pacific}

In addition to establishing and expanding a bilateral relationship with Tonga, China has also developed relationships with several other countries in the region. China has taken a very economically-based approach to its relations with other South Pacific states. To highlight the nature of China's relationship with other states in the South Pacific, and the differences compared to its relationship with Tonga, the following features will be analysed: the role that natural resources play, the role of undemocratic regimes, and the nature of military cooperation.

The South Pacific possesses significant natural resource reserves, which have become a significant attraction for developing economies like China. This is due in large part to the abundance of natural gas, timber, and other minerals that exist in some South Pacific states. As a developing economy, China is on a global hunt for access to more and more resources, to fuel its economic modernisation. This has influenced its relations with several states in the South Pacific, and differs significantly from the nature of its relations with Tonga. This is because Tonga does not possess significant natural resources like natural gas, timber or minerals outside of seabed deposits which are expensive to access. The largest source of these types of resources for China in the region is from Papua New Guinea. This is due to PNG's large reserves of copper, gold, oil and natural gas, which account for most two-thirds of its export earnings. The British Geological Survey reported that Papua New Guinea produced 850,000 tonnes of copper between 2006 and 2010.185 This makes PNG one of the top producers of copper in the world, as well as other valuable minerals. China has formed a strong relationship with PNG, in part to secure access to these natural resources, which can be seen in its development of mining projects through Chinese private-sector mining companies. One such example of this is the Ramu Nickel project, which is operated by Chinese mining company, China Metallurgical Group Corporation. This project is Papua New Guinea's largest foreign investment, as it is 85 percent owned by CMGC. ${ }^{186}$ The Ramu Nickel project is one example of China's

\footnotetext{
185 Brown, T., Walters, A., Idione, N., Shaw, R., Wrighton, C., Bide, T., World Mineral Production 20062010, (Nottingham: British Geological Survey, 2012), p.19

186 Singh, Shivani, "Papua New Guinea's Ramu Nickel Project 'Operating as Normal'", Metal Bulletin, April 122012
} 
involvement in the mining industry in the South Pacific, which has become an important source of minerals such as nickel, cobalt and gold. This has resulted in significant increases in China-PNG trade, as China seeks to increase its access to the minerals it needs for its modernisation programme. This is highlighted by ANZ in their annual statement on Pacific economies. Exports from PNG to China almost doubled, reaching $\$ 780$ million between 2009 and 2010.187 The importance of natural resources such as minerals to China's modernisation is highlighted when PNG exports are compared to the total exports from the South Pacific to China. In 2010 the South Pacific exported \$1.1 billion worth of products to China. ${ }^{188}$ PNG's natural resource exports accounted for 70.9 percent of all exports from the South Pacific to China in 2010. Another South Pacific state that has become an important source of natural resources for China is the Solomon Islands. This is due to large reserves of timber, which China is seeking greater access to as demand for timber grows exponentially in its domestic market. ${ }^{189}$ This Chinese demand for timber has driven the expansion of its relationship with the Solomon Islands. Statistics show that Solomon Island exports to China increased by over one hundred percent to $\$ 66$ million between the 2005 and 2006 financial years. ${ }^{190}$ This contrasts with the ChinaTonga relationship, due to the relative lack of natural resources compared to states like PNG and the Solomon Islands. The abundance of natural resources has influenced the importance of China's relationship with these states, compared to its relationship with Tonga. This is evidenced by the heavily tilted trade statistics for the South Pacific region. The cases of PNG and the Solomon Islands highlight the differences between China's relationship with Tonga and its relationship with other South Pacific states, due to the role of natural resources and how they have influenced the nature of the relationship.

Another aspect of China's relationship with the South Pacific that differs from its relationship with Tonga is the nature of its relationship with fellow non-

\footnotetext{
187 Gruenwald et al., Pacific Quarterly, p.2 188 Ibid ${ }^{189}$ Nadkarni, Dev, "Logged to Death", NZ Herald, July 142007 190 BBC Monitor, "Solomons' Trade Balance with Australia Declines, China, Japan Increases", BBC, September 52006
} 
democratic regimes in the region. The nature of China's relationship with nondemocratic regimes is significant, because it differs significantly from the relationship that China has developed with Tonga. The most visible non-democratic regime in the South Pacific is Fiji, which suspended its democracy following a military coup in 2006. This has allowed China to adopt a stance that differentiates it from the other major regional powers. This has allowed China to assume the role of Fiji's closest ally, providing aid, trade, military cooperation and a powerful voice in international organisations. The suspension of democracy in Fiji has led to a deterioration of official relations with its traditional allies, Australia and NZ. This has opened up a gap that China has moved into, allowing it to evolve its relationship with the Fijian regime. China has become a vocal supporter of Fiji's sovereignty, and Fiji has also expressed support for Chinese sovereignty. This is significant, because it allows the Fijian regime to remain represented within international organisations. China joins several other developing states in ensuring Fiji retains a voice globally, these other states include India, Japan and Indonesia. This is due to China's refusal to follow the lead of Western powers in condemning the military coup. ${ }^{191}$ Following China's refusal to condemn the Fijian military coup, Fiji spoke out in support of its ally following the deadly riots in Lhasa and China's deadly actions in suppressing the riots. ${ }^{192}$ These examples of reciprocal support for actions that were criticised by the West highlight the importance of this relationship.

The Fiji-China relationship is beneficial to both sides, due to complimentary objectives held by each state. To properly examine this, the motives of both states will be analysed to show how the relationship differs from the China-Tonga relationship. The major overarching motive that has driven China's commitment to Fiji is the need to keep Taiwan out of the country. Despite Fiji's adherence to the "One China" policy, it is one of the few South Pacific states to also house a Taiwan Economic Office. ${ }^{193}$ Any attempt by China to follow the Western powers in condemning the military regime would likely see Taiwan move in to take advantage of the situation. This is highlighted by Hanson, who states in a recent opinion piece that "on the one hand, Western states are asking it (China) to help isolate the new dictatorship in Fiji. On the other, China faces the risk of losing a Fiji starved of funds

\footnotetext{
${ }^{191}$ Fiji Times, "China Likes to Help Developing Nations", Fiji Times, November 102007 192 Fiji Times, "Bainimarama Backs Stand on Tibet", Fiji Times, March 292008 ${ }^{193}$ Hanson, Fergus, "Don't Ignore the Big New Player in Fiji", Sydney Morning Herald, May 92008
} 
to its renegade province, Taiwan". ${ }^{194}$ One way that China's relationship with the military regime in Fiji differs from its relationship with Tonga is through the willingness of China's top leadership to visit the country. Fiji's status as a pivot state in the region is also an important factor in the Chinese relationship. Fiji was the first state in the South Pacific to host a visit from Chinese premier Wen Jiabao, in 2006. ${ }^{195}$ During such visits, Chinese leaders have also provided moral support to the military regime against Western pressure. This is evident in the 2007 interview on Fiji TV with the deputy director of the Chinese Ministry of Foreign Affairs, Deng Hongbo. In the interview, he states that Western powers must take a more understanding approach to its engagement with Fiji. ${ }^{196} \mathrm{He}$ also calls for no unilateral action against Fiji, and expresses support for Fiji's plans to hold democratic elections. ${ }^{197}$ China's desire to keep Taiwan out of Fiji has complimented the Fijian military regime's motives for greater cooperation with China. The regime's motives for greater cooperation rest on the need to circumvent the efforts of traditional regional powers to force it to reinstate democracy in Fiji. This is largely due to the willingness of China to act as an alternate source of political and economic support. China has been a vocal supporter of the Fijian military regime since it took power in 2006. This has allowed Fiji to maintain a vocal presence in the region, and in international organisations. China spoke out following the coup, stating that it did not wish to become involved in Fiji's internal politics and respected its status as an independent nation. ${ }^{198}$

This political support from Fiji has been associated with Chinese financial aid, which has largely picked up the slack left by Australia and NZ, after they imposed sanctions on the country following its coup. ${ }^{199}$ This is evident in statements made by Fijian officials, which emphasise the closeness of Fiji's relationship with China. At the opening of a bridge built with Chinese funds, the Fijian vice-President was quoted as saying that the China-Fiji relationship is one of its most important. ${ }^{200}$ China has also been critical of great power chauvinism in Fiji. These examples are significant,

\footnotetext{
194 Ibid

195 AFP, "Chinese Premier Wen to Visit the Pacific Islands", Taipei Times, April 32006

${ }^{196}$ RNZ International, "China Calls for More Understanding from Fiji's Neighbours", Radio New Zealand, November 292007

197 Ibid

198 Fiji Times, "China Likes to Help Developing Nations"

199 MFAT, "Frequently Asked Questions About New Zealand's Policy Towards Fiji", 2010, http://www.mfat.govt.nz/Foreign-Relations/Pacific/0-Fiji-FAQ.php (accessed November 2, 2012)

200 BBC, "China Support for Fiji Questioned", BBC, June 192009
} 
because it highlights the important role that Fiji's non-democratic regime has played in enhancing the relationship between the two countries. This is also significant in that it is not evident in Tonga, which as a constitutional monarchy has partial democracy. This suggests that the similarly non-democratic nature of the two countries' regimes have been a major influencing factor in their relationship.

The final Chinese policy that is significantly different from its policies with Tonga is its use of some South Pacific states as venues to further its military-related programmes. This has created issues around the nature of China's presence and the related instability that these installations and programmes can cause to the region. The South Pacific is geographically suited for China's growing presence in the spheres of defence and space technology. As part of this, it has become involved with South Pacific states to develop its capacities in these areas. China's space programme has created controversy in the region, as other Pacific powers accuse the country of using it as a cover for surveillance on its military operations. This is particularly evident in the case of Kiribati's decision to allow China to establish a satellite tracking station on one of its atolls. The US expressed concerns that China was using the satellite tracking station as cover to conduct surveillance on the nearby US military facilities. ${ }^{201}$ This project was subsequently abandoned by Beijing after Kiribati switched recognition to Taipei. This example is significant, because it shows that China's defence policies make its conduct with other South Pacific states significantly different from its conduct with Tonga.

The second area that makes China's conduct with South Pacific different from its relationship with Tonga is the area of defence cooperation. China provides limited assistance to Tonga's military; however this assistance is in the form of logistics, such as new uniforms and vehicles. China's defence cooperation with other South Pacific states is more advanced than its cooperation with Tonga. China is increasingly expanding its defence cooperation with several South Pacific states, despite its assurances that it is not seeking to establish a base in the region. News reports claim that China is expanding its defence cooperation with the militaries of PNG and Fiji. This is significant because it highlights a shift in approach that is not evident in its relationship with Tonga. This suggests that China's objectives in each country

201 Skehan, Craig, "Pawns in a Diplomatic Poker Game", Sydney Morning Herald, December 182004 
determine the nature of its relationships. China's expansion of military cooperation with Fiji can be attributed to the increasing importance of its relationship with the military regime. The increasing military relationship between China and Fiji was highlighted in a media article about the increasing US concern about China's growing role in the region. ${ }^{202}$ This example suggests that China's increasing military relationship with Fiji is coinciding with its growing wider relationship with the country, which may provide an explanation for why it is expanding its military cooperation with the country.

This correlation can also be seen in the growing military relationship between China and PNG. China's close economic ties with PNG in the area of gas and mineral exploration make it a strategically important partner, as part of its modernisation programme. The expansion of military cooperation between China and PNG comes at the same time as Chinese companies are investing greater amounts of capital and labour into mining operations in the country. The nature of China-PNG military cooperation began with the provision of non-combat logistical equipment, and training exchanges between the two militaries. ${ }^{203}$ In recent years however, there have been calls from the Chinese and PNG governments to expand the military relationship. Chinese defence minister Liang Guangli stated at a recent bilateral meeting that China was ready to take substantial measures to advance military ties to a new level. ${ }^{204}$ This example is significant, because it shows a willingness on the part of China to expand the military ties between it and PNG, as it also expands its economic ties. China stands to benefit considerably from this expansion in military ties, as it strengthens PNG's adherence to the One-China policy. ${ }^{205}$ This suggests that China is seeking to indirectly protect its investments within PNG, by ensuring that the PNG defence force is able to ensure stability and security within the country.

The cases of China's expansion of its satellite programme and its willingness to expand military assistance within the region are significant in that they are not seen in its relationship with Tonga. This evidence suggests that China is not prepared to risk destabilising its relationship with Tonga or to create the risk of confrontation

\footnotetext{
${ }^{202}$ Herr, Richard, and Anthony Bergin, "U.S. Moves to Counter China in Pacific", The Australian, December 12011

${ }^{203}$ Australian Associated Press, "PNG Strengthens Ties with China", Courier Mail, June 302009

${ }^{204}$ Xuequan, Mu, "China, Papua New Guinea Vow to Expand Military Cooperation", Xinhua, June 26 2009 205 Ibid
} 
with the US over it. This is important because it also suggests that China values its relationship with Tonga and does not wish to jeopardise it.

The analysis of China's quest for natural resource access, support for nondemocratic regimes and increasing military cooperation highlights significant differences that exist in China's relationship with Tonga and its relationships in the wider South Pacific region. The analysis has shown that while China is drawn to other countries primarily for their natural resources, political similarities or suitability for advancing China's own programmes, its relationship with Tonga is not based solely on these priorities. Despite efforts by China to introduce soft power-based initiatives in other countries in the region, the policies that differ from its relationship with Tonga could be considered as expressions of hard power. The following section will analyse China's provision of scholarships to Tongan students as a form of soft power to improve its image, at that same as it is expanding its political and economic engagement with Tonga. 


\subsection{Chinese provision of scholarships in Tonga}

The expansion of the China-Tonga bilateral relationship created tensions among Tongan citizens threatened by the increasing Chinese presence in Tongan society. China has complimented its increasing political and economic engagement with an increasingly significant attempt to educate ordinary Tongans as to its culture, values and role in their country. China has undertaken this by promoting educational exchanges to China for Tongan students, using scholarships that allow students to travel to China to further their studies and learn about Chinese culture and values. China's scholarship programme in Tonga will be analysed to show that China has used these scholarships as a form of soft power to pave the way for its increasing political and economic engagement. To accomplish this, the chapter will analyse the components of the scholarship scheme, to identify what it is they provide. Following this, the number of scholarships provided by China each year will be analysed to examine how this reflects the China's soft power objectives. The number of scholarships accepted by Tongan students each year will also be analysed. Finally, the relationship between the provision of these scholarships and the expansion of China's political and economic engagement will be analysed, to identify correlations, trends or anomalies in the relationship.

\section{Scholarship Components}

China has become an increasingly attractive option for exchange students. In 2012 four Chinese universities broke into the top one hundred rankings, up from two on the previous year. ${ }^{206}$ China provides scholarships to study abroad for a number of tertiary students in Tonga, allowing them to study in China and learn about Chinese culture, values and society. The provisions included within these scholarships provide an insight into Chinese efforts to educate Tongan students as part of its engagement with the country. The scholarships provided by China include several

\footnotetext{
206 Schuetze, Christopher F., "Asian Universities Jump in Rank; While Recruiters Still Put the U.S. And Europe on Top, China Is Moving Up", The International Herald Tribune, October 252012
} 
mechanisms with which the students on exchange are exposed to China's culture, values, and society. These mechanisms include the type of accommodation provided, the allowances provided to students for travel, and Chinese language training. These mechanisms will be analysed to show how they are increasing Tongan students' understanding of China, and how this is making it possible for China to enhance its political and economic engagement with Tonga.

When students accept scholarships to study abroad, accommodation becomes an important part of the student's time in that country. Accommodation can play a significant role in shaping the opinions held by students who participate in these exchanges, as it exposes them to the culture, values and language of that country. This is also true of China's scholarships for Tongan students to study abroad, and includes mechanisms to influence the perceptions of Chinese culture held by these students. Culture, as identified by Nye, is an important part of soft power. It possesses significant powers of attraction, primarily due to its ability to exist at multiple levels of society. Because of this, it has become important for states wishing to enhance their soft power to educate the peoples they are targeting about their culture. It is for this reason that the type of accommodation provided by China within their education scholarships is important to its efforts to enhance its soft power among Tongans. The most frequent accommodation option offered in the scholarships is the provision of financial allowances to allow the exchange students to live in campus dormitories at the chosen university. The choice of dormitories as the preferred accommodation for exchange students is important, because it places them in an environment that maximises their opportunity to be exposed to Chinese culture and values. This provision is set out in the terms and conditions of the major scholarships available to Tongan students. The terms and conditions of the China-PIF Scholarship Programme set out that exchange students will be provided with accommodation in campus dormitories, and be exempted from paying accommodation fees for these dormitories. $^{207}$

The provision of dormitory accommodation is significant to the projection of soft power on the part of China, because it allows China to shape the way that these

207 China Scholarship Council, "China/PIF Scholarship Programme", 2012,

http://en.csc.edu.cn/Laihua/scholarshipdetailen.aspx?cid=97\&id=1286 (accessed November 19 2012) 
students experience Chinese culture and values. This form of accommodation is conducive to enhancing the perceptions of exchange students, because housing these students within campus dormitories means that they are living with fellow students, which allows them to experience the culture and values that influence the lives of Chinese students. This is due in large part to the growing attractiveness of Chinese film, theatre, herbal medicine, cuisine, martial arts and other aspects of Chinese culture that have become increasingly popular. This is evident in the renewed focus on advertising Chinese culture by government officials. The South China Morning Post reports that culture is to play a vital role in the latest five year plan; to boost China's soft power. ${ }^{208}$ The decision by the Chinese government to use dormitory accommodation for Tongan exchange students is significant, because it suggests that this accommodation type is being used to expose the students to Chinese culture and values, to enhance its soft power. This is also evidenced by the statements made by Chinese officials of the need to further promote the Chinese culture as part of its wider efforts to enhance its soft power.

A second important component of scholarships to study overseas has been the allocation of travel allowances for students. This is significant to the analysis of Chinese efforts to enhance its soft power among Tongan exchange students, because travel allowances allow these students to visit sites around China and learn more about its history and culture. The role of culture in enhancing soft power is already well-known, but the ways in which culture can be exploited or taken advantage of is still relatively new. It is in this way that China is able to take advantage of its rich culture and heritage to enhance the soft power it is seeking to wield with Tongan exchange students. China's history is a rich source of soft power, as it is becoming increasingly attractive to other countries. China has made its history and culture more well-known by better advertising it on the world stage. One of the efforts made by China to make its culture more well-known is the use of "panda diplomacy" to develop people-to-people relationships with other countries using this cultural

208 Jiao, Priscilla, "Culture a Key Priority in Five-Year Plan; Leaders Hope Industry Will Help Bolster Nation's 'Soft Power' Abroad; Cynics Fear Waste", South China Morning Post, March 282011 
symbol. ${ }^{209}$ This has contributed to the increasing attractiveness of study in China, by using such symbols to educate foreigners about Chinese culture and history.

This has made it possible for China to enhance its soft power in Tonga by using scholarships to enable Tongan exchange students to experience Chinese history and culture. This is due to components of the scholarships themselves, which provide financial allowances that incentivise travel outside of the cities that they are studying. This is provided as a broadly-defined "living allowance", a monthly payment made to exchange students as part of their study in China. This monthly payment varies depending on the type of degree that students are studying towards, ranging from 1,400 yuan per month for undergraduate students or Chinese language students, to 2,000 yuan per month for PhD candidates and senior scholars. ${ }^{210}$ This living allowance is provided in both of the major scholarships provided by China for Tongan students. These allowances are significant, because they allow exchange students studying in China to take part in activities outside of study in China. These allowances provide incentive for exchange students to visit other parts of China, because they are funded by the Chinese government. The terms and conditions of the scholarships do not specify what the living allowance must be used for, which further incentivises travel to learn more about Chinese history and culture. An example of the benefits of Chinese scholarships in allowing exchange students to travel in China to experience the history and culture is the case of two exchange students from New Zealand, who received a Chinese government scholarship. Students explain that they would spend their breaks between trimesters travelling in China to gain experience learning the language. ${ }^{211}$ The evidence highlighted here suggests that the living allowances provided by these scholarships are allowing students to travel to other parts of China to learn more about the country, which can enhance the soft power that China is seeking to wield in Tonga.

The final component of the scholarships provided by China for Tongan students to study in China that can be suggested to enhance its soft power is the

\footnotetext{
${ }^{209}$ Kuang, Heng Yee, "Power That Speaks Softly; from Panda Loans to Pop Culture, Countries Compete to Project Soft Power", The Straits Times, September 82012

${ }^{210}$ China Scholarship Council, "China Government Scholarship Programme", 2012, http://www.csc.edu.cn/laihua/scholarshipdetailen.aspx?cid=97\&id=1422 (accessed November 26 2012)

211 Dominion Post, "Scholarships Take Students to China", Dominion Post, November 12012
} 
provision of language training. The literature on soft power has identified language as a critical component in a state's soft power currencies, which can enhance the attractiveness of a state. Demand for Chinese language education is rising in the West, as China becomes a more important source of employment and business. China has already been shown to be actively using its language abroad to educate and attract foreign peoples through the establishment of Confucius Institutes. This use of language to enhance Chinese soft power has been expanded by the Chinese government to include exchange students who study in China. This is important to the Chinese efforts to enhance their soft power among Tongans, because providing language training ensures that exchange students are able to become fully immersed in Chinese society. The experiences of exchange students from other participating countries show the strength of language training in enhancing Chinese soft power. This is because their experiences can be considered to be similar to the experiences of Tongan students. The experiences of exchange students in China suggest that language education has become an integral part in enhancing China's soft power. This is due to the growing sentiment from these students that an understanding of the language is necessary to fully appreciate the cultural nuances of China. ${ }^{212}$

To take this into account, the Chinese Scholarship Council has made language training an important part of its scholarship programmes for Tongan students. This is usually in the form of a preparatory language class to be attended by exchange students before they commence their studies in China. ${ }^{213}$ This provision is included in the China-PIF scholarships and the Chinese Government scholarships, both of which are available to Tongan students. The inclusion of language training by the Chinese government in the scholarships it provides to Tongan students is significant, because it suggests that China wants to ensure that Tongan students are able to fully immerse themselves in Chinese culture and history. This can enhance the soft power opportunities for China among these students, as they will be better prepared to understand and appreciate Chinese culture.

This section has highlighted three mechanisms adopted by China in their scholarships to enhance the soft power that they hope to wield within Tonga. These

\footnotetext{
${ }^{212}$ Hoare, Stephen, "Inspiration from the East: Why Not Study in Asia?", The Independent, September 202012

${ }^{213}$ CSC, "China Government Scholarship Programme"
} 
mechanisms are the type of accommodation provided, the allocation of living allowances, and the language training provided to exchange students. These mechanisms are important to China's efforts at enhancing its soft power in Tonga, because they enable the Tongan exchange students to become more exposed to China's culture, values and heritage.

\section{Scholarship Provision}

The previous section analysed the scholarships provided by China for Tongan students to study abroad, which have been shown to have the ability to enhance Chinese soft power. This section seeks to analyse China's provision of scholarships for Tongan students, and how this correlates with its increasing political and economic engagement with Tonga. To accomplish this, the section will first examine the role of the Chinese government in scholarship provision, to show how the government is involved in these scholarships. Following this, the yearly scholarship provision rates will be analysed to identify any trends and correlations between this and the political and economic engagement. Finally, the numbers of scholarships that are accepted by Tongan students will be analysed, to determine whether Chinese efforts to enhance its soft power among Tongan students have been successful.

The Chinese Government has operated its scholarship programme for several years, through its non-profit organisation, the China Scholarship Council, which is affiliated with the Chinese Ministry of Education. This organisation was established in 1996, and is responsible for the implementation of scholarships for foreign students to study in China, and financial support for Chinese students studying abroad. The CSC plays a central role in the administration and provision of scholarships for foreign students. This is because the CSC is responsible for implementing the scholarships of Tongan students wishing to study in China. The CSC states that it is responsible for strengthening friendship and ties between the Chinese people and peoples of other countries through educational exchanges. ${ }^{214}$ The CSC goes on to state that it is responsible for educational, scientific, and cultural exchanges between

${ }^{214}$ China Scholarship Council, "China Scholarship Council", 2012, http://en.csc.edu.cn/About/c309df7fb3fa40b3a179a7ad93f11988.shtml (accessed November 30 2012) 
China and other countries, and also encouraging trade and economic cooperation. ${ }^{215}$ This description of the role of the CSC suggests that the Chinese government is prioritising the use of scholarships as a form of soft power provision. This is due to the importance placed on strengthening the ties between Chinese peoples and the peoples of other countries, as has been shown by the objectives of the CSC. This is important for the analysis of Chinese provision of scholarships for Tongan students, and its correlation with soft power development in Tonga, because it shows that China considers education to be an important source of soft power.

China has gradually made scholarship provision in Tonga an important part of its bilateral relationship with the country. This is evident in the statistics surrounding China's provision of scholarships to Tonga in the last decade. The provision of scholarships by China to Tonga can be considered a significant aspect of its programme to enhance its soft power in the country, at the same time that it also seeks to expand its political and economic engagement. This is due to the growing need to make ordinary Tongans more aware of China and its culture, as it seeks to expand its relationship. China's provision of scholarships for Tongan students began at a relatively low level. The Tongan Government revealed that China provided between ten and fifteen scholarships for Tongan students in 2005. ${ }^{216}$ This suggests that China did not place such an emphasis on the importance of education as part of its quest for greater soft power, at this time. It may also suggest that China did not put much focus on soft power as it started to expand its relationship with Tonga. This is significant, because it suggests that China's relationship with Tonga was not well developed at the level of people-to-people relations, due to the lack of expansion of education exchanges. This may be attributed to the China-Taiwan rivalry, which was a major factor in China's engagement with the South Pacific during that period. To counteract this, China has used scholarships to study abroad to aid in the people-topeople relationship it seeks to gain in the country. This is evident in the increase in yearly scholarship provision between 2005 and 2011. The Tongan government states that in 2011 the Chinese government made available thirty scholarships for Tongan students to study in China. This is an increase of one hundred percent on the 2005

215 Ibid

216 Interview with South Pacific diplomat, May 202011 
figure. This figure suggests that China is putting increased focus on education as a soft power tool to develop its relations with the Tongan people. This is significant, because it is evidence of a greater effort by China to exert soft power within Tonga, as part of its bilateral relationship.

The provision by China of scholarships for Tongan students to study in China has been shown to be a rapidly-evolving aspect of the bilateral relationship between the two countries. The rate of provision of these scholarships has been significant in influencing the soft power that China possesses in Tonga, as it has been suggested that many students who participate in Chinese education exchanges go on to become influential figures in their home governments. This suggests that the provision by China can be an effective tool for enhancing the soft power that it wishes to wield in the island state.

\section{Scholarship Acceptance}

At the same time that China has increased its scholarship provision to Tonga, ever increasing numbers of Tongan students are accepting these scholarships to study in China. This is important for the analysis of how these scholarships enhance China's soft power in Tonga, because the rate of acceptance by Tongan students provides insight into the effectiveness of Chinese soft power. The scholarship acceptance rates among Tongan students suggest an increasing desire to learn about China, and to gain a qualification from a Chinese institution. This suggests that China is becoming a more attractive destination among Tongan students.

The statistics for scholarship acceptance among Tongan students shows that early on in its development, it was not an effective tool for developing soft power. Between 2003 and 2005 only six scholarships were accepted by Tongan students to study in China. ${ }^{217}$ This is broken down to two scholarships being accepted each year during this period. ${ }^{218}$ This is significant, because it highlights the issues facing China in its provision of scholarships early on in its relationship with Tonga. The low number of scholarships accepted by Tongan students between 2003 and 2005 suggests that China's scholarship programme was not an effective source of soft

${ }^{217}$ Telefoni, Pelenaise (Tongan diplomat, Scholarships Unit), email message to the author, October 18, 2012 
power. Despite this, the number of Tongan students accepting these scholarships rapidly increased following the 2003-2005 period. From 2006 until 2010, 117 Tongan students accepted scholarships to study in China. ${ }^{219}$ This scholarship acceptance reached a low of fifteen in 2008, and a high of twenty-nine in 2009. 220

These statistics suggest that China is becoming a more attractive destination for Tongan students. This could be attributed to the attractiveness of its culture, as China has become a more popular destination for international students. The increase in acceptance of these scholarships has come at the same time as China is increasing its bilateral relationship with Tonga. This suggests that China is placing more focus on these scholarships as part of its programme to enhance understanding of China by ordinary Tongans. This increase in popularity of Chinese scholarships is important for the soft power efforts being undertaken by China. This is because by having more Tongan students study in China, it increases the opportunities for ordinary Tongans to be educated about China and its culture, from the students who have studied there. The Tongan students who study in China on these scholarships play an important role in China's push to enhance its soft power within the country. They act as sources of information about and attraction towards China, due to their experiences there and knowledge of its culture and values. This is important, because interactions between Tongans are more common than interactions between Tongans and Chinese government officials, so by exposing Tongan students to China and its culture the Chinese government is able to enhance its soft power more effectively than by directly intervening. The analysis of scholarship acceptance rates in Tonga has highlighted a correlation between the increase in scholarship acceptance and the expansion of the China-Tonga bilateral relationship. This correlation has been suggested to be a significant contribution to China's quest for greater soft power in the country.

This section has analysed the Chinese government's role in the provision of scholarships to study in China, and the effect that these scholarships may be having on Chinese soft power in Tonga. A correlation between the increase in scholarship

\footnotetext{
219 Anonymous (South Pacific diplomat), email message to the author, September 1, 2011 220 Ibid
} 
provision and acceptance rates, and the expansion of China's bilateral relationship has been identified, which is significant to the discourse on Chinese soft power in the South Pacific. This can be suggested to be due to the role of soft power in paving the way for greater engagement between states. The following section will compare this relationship to the relationship China has with South Africa, to highlight similarities and differences in its relationships in each region. 


\subsection{Does the China-Tonga relationship compare to the rest of the world?}

The China-Tonga bilateral relationship has been shown to be making significant advances in the realm of soft power, largely through the use of scholarships for Tongan students to study in China. But how does this compare to China's other relationships? To better appreciate the China-Tonga bilateral relations, it must be compared to one of China's other relationships. To better understand this, China's bilateral relationship with South Africa will be analysed in comparison to its relationship with Tonga. To accomplish this, the section will first examine the nature of China's relationship with South Africa, in terms of politics, economics and culture. Following this, the acceptance rates of the same types of scholarships will be analysed. Finally, this will be compared to the China-Tonga relationship to identify similarities, differences and unique factors of China's foreign relations with these two countries.

China's bilateral relationship with South Africa is a significant one, due in large part to South Africa's abundant natural resource wealth and geostrategic position. China's relationship with South Africa is comparatively new, with official recognition only gained in 1998. Since then, China has rapidly expanded its relationship with South Africa, both economically and politically. ${ }^{221}$ It has also made progress in exerting its soft power within the country, as evidenced by a number of programmes. The political relationship between China and South Africa is based on reciprocal diplomatic visits, at multiple levels of government. ${ }^{222}$ This often takes the form of state visits by high-level diplomats. These high-level visits are focused on a number of issues important to both sides. Examples of important issues that have resulted in official visits are energy, trade, defence, and international development. ${ }^{223}$ Both countries are also members of the BRICS group, an association of emerging economies that are fast-growing. In 2012, Chinese Vice President Xi Jinping visited

\footnotetext{
${ }^{221}$ Embassy of the People's Republic of China in the Republic of South Africa, "Ever-Deepening ChinaSouth Africa Strategic Partnership", 2006, http://www.chineseembassy.org.za/eng/zt/06wen/t257544.htm (accessed December 10, 2012)

222 Ibid

223 Ministry of Foreign Affairs of the People's Republic of China, "Bilateral Relations", 2011, http://www.fmprc.gov.cn/eng/wjb/zzjg/fzs/gjlb/3094/ (accessed December 7, 2012)
} 
South African President Jacob Zuma. 224 This meeting concerned the development of the China-South Africa Comprehensive Development Partnership, an important mechanism for strengthening their relationship. This is highlighted during Vice President Xi's visit, where he stated that China will make joint efforts with South Africa to strengthen high-level visits, party exchanges, deepen communication, and optimise trade and mutual investment. ${ }^{225}$ This example highlights the significant political importance of the China-South Africa relationship, as it is a mechanism for advancing wider south-south relations.

China's economic ties with South Africa have formed an integral part of its wider bilateral relationship. This is due in large part to the importance of minerals to China, as part of its economic modernisation programme. South Africa's mineral wealth forms a significant part of its economy, as is evidenced by its major exports. South Africa's major exports are gold, platinum, diamonds, and other metals and minerals. ${ }^{226}$ This is important for China, as it relies on these minerals to drive its economic modernisation. China has also used trade as a way to develop its soft power in South Africa. This is evident in trade statistics, which show that in 2009 China was the largest export destination for South African goods. ${ }^{227}$ China also provides significant financial aid, in the form of loans. The Financial Times reported that China pledged $\$ 20$ billion in loans to South Africa this year alone. ${ }^{228}$ This expansion of the trade relationship between China and South Africa, and the increasing provision of financial aid, highlights the importance that China places on the relationship. This is not to say that there are no concerns about the nature of this relationship. South African President Zuma identified the unbalanced nature of the trade relationship as a source of instability in the long term. ${ }^{229}$ This is significant, because it shows that South Africa's leadership is aware of the possible repercussions of greater Chinese engagement.

\footnotetext{
${ }^{224}$ Ministry of Foreign Affairs of the People's Republic of China, "Vice President Xi Jinping Meets with South Africa's President Zuma", 2012, http://www.fmprc.gov.cn/eng/zxxx/t954393.htm (accessed December 7, 2012)

225 Ibid

226 Central Intelligence Agency, "South Africa", 2012, https://www.cia.gov/library/publications/theworld-factbook/geos/sf.html (accessed December 7, 2012)

227 Reuters, "China Becomes S.Africa's Top Export Destination", Reuters, October 22009

228 Hook, Leslie, "Zuma Warns on Africa's Ties to China", Financial Times, July 192012

229 Ibid
} 
China has also made greater efforts to enhance the cultural relationship that exists between it and South Africa. China has become more active in promoting its culture in South Africa, through a number of different mechanisms. These include the broadcasting of Chinese media into South Africa, the provision of language education for South African students, and the promotion of tourism. ${ }^{230}$ This change in approach by China was initiated in 2004 with a large cultural event titled "Bravo China Chinese cultural tour to South Africa". ${ }^{231}$ This tour consisted of a series of cultural activities aimed at "experiencing China", which took place in South Africa. ${ }^{232}$ This change in approach to the China-South Africa cultural relationship has resulted in a much greater exposure to Chinese culture for South African citizens, often in the areas of education and tourism. These measures include the provision by China of approved destination status for South Africa, which increases the number of Chinese tourist groups visiting the country. ${ }^{233}$

China has introduced education exchanges for South African students to study in China, which enables them to experience Chinese culture and values. In 2006 there were three thousand South African students studying in China. ${ }^{234}$ The examples provided here highlight the evolving nature of China's cultural relationship with South Africa, as it seeks to enhance the ties that bind the two countries. China's evolving relationship with South Africa has evolved from a limited partnership based on trade and political recognition, to one that encompasses trade, political partnerships and culture. This highlights the significance of the relationship to both sides.

The acceptance rate for scholarships provided by China for South African students to study in China has undergone a significant evolution, as China becomes a more active player in South African society. China's provision of scholarships to South African students began in 2003, at a relatively low level. Government statistics show that in 2004, four scholarships were provided for South African students to study in

\footnotetext{
230 MFA, "Bilateral Relations"

${ }^{231}$ Embassy of the People's Republic of China in the Republic of South Africa, "Ever-Deepening ChinaSouth Africa Strategic Partnership

232 Ibid

233 Ibid

234 Ibid
} 
China. ${ }^{235}$ This figure is significant, because it suggests a low level of interest in these scholarships early on in the bilateral relationship. This may be the result of a number of factors, such as the limited nature of the relationship during this time, as China only began to put extra focus on its culture in 2004, the year after these scholarships began. The relatively low number of students who accepted Chinese scholarships in 2003 suggests a correlation between it and the state of the China-South Africa relationship, which suggests that there is a link between the role of culture in bilateral relations and the attractiveness of student exchanges. This is because the expansion of the China-South Africa relationship led to the expansion of cultural ties between the two countries. Chinese feature heavily in South African history, being brought into the country by the Dutch as convict labour in the seventeenth century. ${ }^{236}$ This cultural history has been built on by China, with the establishment of Confucius Institutes across the country, to educate South African students about Chinese culture. ${ }^{237}$ This is significant for the analysis of soft power, because it highlights the importance of attractiveness as a key feature of soft power cultivation.

As the China-South Africa bilateral relationship has evolved, so has the level of scholarship acceptance. In the period after the initiation of the "Bravo China" cultural programme, the rate of acceptance of Chinese scholarships has gradually increased. South African statistics show that the number of scholarships accepted increased from two per annum in 2004 to twenty-four per annum in 2012.238 During this period, a total of 113 scholarships were accepted by South African students to study in China. ${ }^{239}$ This is an average of twelve scholarships per year during the stated period. This is significant, because it highlights the increasing attractiveness of China as a destination for students. This suggests that the cultural programme introduced by China in 2004 has enhanced awareness, which in turn has made China a more attractive option for exchange students. This can be said to be enhancing the soft power being wielded by China in South Africa, due to the increasing numbers of students being exposed to Chinese culture and values during their time abroad. This

\footnotetext{
235 Ntshinga, Madoda, (Deputy High Commissioner, South African High Commision, Wellington), email communication to the author, December 3, 2012

${ }^{236}$ Harris, Karen, "Waves of Migration: A Brief Outline of the History of Chinese in South Africa", in Martyn Davies (ed.), The China Monitor (Stellensbosch: Centre for Chinese Studies, 2007), p.4

${ }^{237}$ Tong, Wei, "Confucius Institute Bridges Friendship between China and Africa", China Radio International, February 172009

${ }^{238}$ Ntshinga, email communication

239 Ibid
} 
is significant, because it suggests that China's use of scholarships as part of its wider cultural programme in South Africa is enhancing its soft power, which can be seen in the increasing numbers of students accepting the scholarships.

This analysis of the China-South Africa bilateral relationship, and the role of scholarships, has highlighted the nature of the relationship and the role that scholarships are playing in China's quest for greater soft power in the country. The question that must be asked now is; does the China-South Africa relationship correlate to the China-Tonga bilateral relationship? Both are important to China and its foreign relations, yet each exhibit subtle differences in need of comparison.

There are several similarities that are apparent in China's bilateral relations with both countries, which suggest a common method of implementation by China of its foreign relations, such as the use of state visits and the recent focus placed on culture. The main similarities concern the approaches to political engagement, the role of culture, and the provision of scholarships by China in both countries. China places considerable emphasis on the role of state visits as part of its political engagement with both countries. This has been shown in the analysis of both bilateral relationships, as China has both made and received several state visits to and from Tonga and South Africa. Visits to both of these countries have frequently involved high-level officials and resulted in progress towards greater cooperation in various areas of concern to both parties. ${ }^{240}$ The use of state visits by China in Tonga and South Africa is important, because it shows that China considers elite-level relations to be a significant aspect of its foreign relations strategy. This is important, because it suggests that in this respect the China-Tonga relationship is not unique, compared to China's wider foreign relations. China's focus on culture can be seen in its bilateral relationships with Tonga and South Africa. This focus on culture in two of China's bilateral relationships, in different regions, suggests that China considers culture to be an important part of all of its bilateral relationships. This is highlighted by the cases of cultural visits to both countries, and the role of Chinese media in both countries. The third similarity in China's relationships with Tonga and South Africa is the use of scholarships as part of its engagement with these countries. This suggests

${ }^{240}$ Ministry of Foreign Affairs of the People's Republic of China, "Vice President Xi Jinping Meets with South Africa's President Zuma", 2012, http://www.fmprc.gov.cn/eng/zxxx/t954393.htm (accessed February 1, 2013) 
that scholarships are considered to be a valuable tool in China's foreign relations strategy. The use of scholarships has been made evident in the bilateral relationships of both countries.

The most important difference in the nature of China's bilateral relationships with these countries is the role that economics plays in each. This is due to the large difference in the state of each country's economy. Tonga's economy can be characterised as being highly dependent on external factors such as China and its generous aid programme. ${ }^{241}$ In contrast to this, South Africa's economy is built on a strong platform of mineral resources which has resulted in a strong economy that is an African leader, despite high unemployment. ${ }^{242}$ This difference in relationships has influenced the nature of the role that China plays in each. This is an important difference, which has had an effect on the way that China has approached its relationship with each country. The similarities and differences in China's relationships with Tonga and South Africa, identified in this section, are significant to the analysis of how it uses soft power in its relationships. To better understand this, the following section will analyse the significance of these similarities and differences to the wider field.

The similarities and differences identified in the previous section are significant, because they provide insight into the role that education is beginning to play in China's quest for greater soft power. These are important, because they highlight the growing importance of education to Chinese soft power, because they show that this is not an aspect unique to China's relationship with Tonga.

The similarities in China's relationships with Tonga and South Africa are significant, because they show that the approach being used by China, specifically the use of state visits, culture and scholarships, is part of China's wider foreign relations. China's promotion of its culture in these relationships is significant, because it suggests that China considers culture to be a universal mechanism for educating the peoples of the countries it has relations with to its values, society, and actions. This is important, because the use of culture by China in both of these relationships relates significantly to the idea of soft power, due in large part to the attractive power of

241 Young, "China's Aid to the Pacific Tops $\$ 800 \mathrm{~m} "$

242 Reuters, "China Becomes S.Africa's Top Export Destination" 
culture. This suggests that China recognises it needs to focus on soft power to enhance its perception at the people-to-people level with other countries. The similarity in scholarship provision can be seen to be correlated with this, because the increase in scholarship acceptance by students in Tonga and South Africa can be suggested to have been caused by the increasing use of culture by China as part of its bilateral relationships. This is important, because it highlights the increasing importance of soft power to China's foreign relations, especially when it has its soft power enhanced by students who were exposed to Chinese culture in China. As it was explained earlier, these scholarships are an effective source of soft power because they expose students to Chinese culture and values, which enables them to educate those in their home countries once they return.

The main difference in the two bilateral relationships, in the nature of the economy, is also significant to the analysis of the role of education on Chinese soft power. The differing nature of each country's economy, from highly dependent to strong if uneven, suggests that the use of education as a soft power tool is universalistic, because it is effective in countries that have very differing economic situations. This is significant, because it makes education a powerful tool for generating soft power. This is because it has been shown to be effective in a number of different scenarios. This difference in China's relationships with Tonga and South Africa has proven to be a significant contribution to the soft power debate, because it shows that education is important to the provision of soft power, due to its universalistic nature. When combined with the attractive power of culture and the increasing awareness of China from its scholarships, both of which are evident in both of the relationships analysed, education has been shown to be an important tool in China's soft power arsenal, because it is able to attract and educate students from other countries who in turn educate others about China. 


\subsection{Conclusion}

China's bilateral relationship with Tonga has been shown to feature high levels of dependence, due to an undeveloped tourism sector, weak exports and high debt, and ethnic tensions that set it apart from China's other relationships in the region. China's relations with the South Pacific feature several examples of hard and soft power, both of which heavily influence China's standing in the region. To off-set the negative consequences of China's engagement with Tonga, it has sought to undertake a number of programmes to enhance its soft power. Among these programmes, the provision of scholarships for Tongan students to study in China has become a significant part of China's quest for greater soft power in Tonga. The provision of on-campus accommodation, travel allowances, and language training can attract these students to China, by educating them about its culture, values and history. The provision rates for these scholarships have been shown to be important to the analysis of China's use of soft power in Tonga.

This is because China has increased the number of scholarships it provides each year, as its bilateral relationship with Tonga has expanded. This can be suggested to reflect an increasing awareness on China's part of the need to educate ordinary Tongans about its presence and nature. The rate of scholarship acceptance provides insight into the effectiveness of these scholarships in enhancing Chinese soft power. This is because there is a correlation between the increase in Chinese cultural programmes in Tonga, and the increasing numbers of students accepting these scholarships. This suggests that as Tongan students are becoming more educated about China; they want to travel to China to learn more. These findings can also be seen in China's bilateral relationship with South Africa, which also makes use of scholarships as part of its quest for greater soft power. The results of this analysis suggest that China is actively using these scholarships to enhance its soft power in Tonga, as it seeks to expand its political and economic engagement with the country. 


\section{Chapter Five:}

\section{Conclusion}

This thesis has examined the role of soft power in China's foreign relations strategy, specifically the relationship between education and China's bilateral relationship with Tonga. This paper has revealed a number of discoveries regarding the importance of scholarships as part of China's quest for greater soft power in Tonga, to pave the way for greater political and economic engagement with the country. These discoveries were made possible by the limited nature of the existing scholarship on the role that soft power plays in China's foreign policy, especially in regards to its relationship with Tonga. This decision was based on a review of the literature, which highlighted an absence of work concerning the role of education in China's soft power approach in Tonga. Because of this, the thesis has analysed China's provision of scholarships for Tongan students to study in China, and how this is paving the way for greater Chinese political and economic engagement with Tonga. The findings of the analysis can be considered to be an important contribution to the academic debate on soft power, and on China's engagement with the South Pacific region as a whole, because it examines the recent Chinese use of scholarships as a form of soft power.

The analysis made in this paper has focused a number of key arguments. These arguments revolved around the nature of the China-Tonga bilateral relationship, how it compares to the wider region, and the use of scholarships by China. The analysis of the China-Tonga bilateral relationship has been important to the wider examination, because it has identified and analysed aspects of the relationship that can be considered unique, compared to the wider region. The analysis of Tonga's dependence on China, and the ethnic tensions resulting from this greater dependence are important, because they suggest that Tonga's dependence on China has created conditions favourable to greater Chinese engagement. The analysis of China's relations with other South Pacific states is important, because it shows that China does not gain the type of natural resource access from Tonga that it does in other countries. China's desire for natural resource access in countries like PNG and the Solomon Islands shows that China does not possess a dependent relationship 
with the rest of the region. These analyses suggest that Tonga's economic dependence has benefitted China, as it has enabled it to further develop the bilateral relationship. The comparison shows that this type of relationship is not evident in other parts of the South Pacific. The second part of the argument focused on the analysis of China's use of scholarships in Tonga. The aim of this part of the argument was to test the hypothesis that China is using the scholarships to enhance its soft power, to pave the way for greater political and economic engagement. The analysis looked at China's provision of scholarships and the rate of acceptance by Tongan students. The analysis of Chinese scholarship provision suggests that China is using them to enhance its soft power, because there is a correlation between the expanding relationship and the increase in scholarship numbers. The analysis of scholarship acceptance suggests that as the China-Tonga bilateral relationship has expanded, so has the number of students accepting scholarships to study in China throughout the South Pacific. To evaluate this argument against China's wider policy, the ChinaTonga bilateral relationship was compared to China's bilateral relationship with South Africa. This comparison involved looking at the similarities and differences of the two relationships, and how significant they are to the analysis.

The hypothesis that was tested in this thesis, that China is providing scholarships to enhance its soft power as part of its quest for greater political and economic engagement with Tonga, has led to a number of discoveries that are important for the field of soft power research. The most important discovery is that the number of scholarships being accepted appears to correlate with the expansion of China's relationship with Tonga. This is important, because it suggests that these scholarships are enhancing China's soft power, which is also allowing it to expand its political and economic engagement with Tonga. This goes some way to proving the hypothesis put forth at the beginning of this paper. Another discovery that is important for the academic debate is the finding that there is a correlation between the expansion of China's bilateral relationship with Tonga and the provision of scholarships. The correlation between the increase in scholarships provided and the expansion of the relationship is important, because it suggests that China is aware of the effectiveness of education in generating soft power. This supports the hypothesis, because it shows that China is making more use of a soft power-generating tool the same time as it is expanding its relationship with Tonga. The third important 
discovery for the hypothesis is that this correlation between soft power and engagement is not necessarily unique to the China-Tonga bilateral relationship. The comparison of the China-Tonga bilateral relationship with the China-South Africa relationship has highlighted a number of important similarities, including the use of scholarships for students to study abroad. This suggests that China is adopting education-based soft power strategies across a number of its relationships. This is important, because it shows that the use of scholarships, while unique in the South Pacific, is not necessarily a unique aspect of China's wider foreign strategy. These discoveries all contribute to supporting the hypothesis that China is using scholarships as a soft power tool to set the stage for greater political and economic engagement with Tonga.

The academic literature on China-South Pacific relations to date has focused primarily on the hard or coercive power being exerted by China in the region. This has meant that China's soft power remains a relatively under-researched aspect of the field. This paper has challenged a traditional focus on hard power in China-South Pacific relations by academics. It has done this by focusing on a significant aspect of soft power, attraction created by education, analysing the role that this plays and the effect that it has had in Tonga. This analysis has challenged the view that hard power is the most important factor in China's relations in the South Pacific. This is because it has suggested that soft power-based initiatives have proven effective at generating attraction towards China, an important factor in generating soft power.

The objective of this paper was to analyse an aspect of China's relationship with the South Pacific that has not been examined previously as part of the academic field. In the course of this analysis, several key discoveries were made regarding this aspect of the studies of non-traditional diplomacy. The first new discovery that was made was the correlation between scholarship provision and relationship expansion. Prior to this research, the analysis of China-Tonga relations focused on hard power aspects, often at the expense of China's growing soft power initiatives. This discovery is new, because research has not been previously undertaken that examines the provision of scholarships by China in Tonga. This is related to the second important discovery that was made in this paper; that the increase in scholarship acceptance by Tongan students correlates with the expansion of China's bilateral relationship with 
Tonga. This is a new discovery, because the research into the China-Tonga bilateral relationship has not previously examined the link between the increasing popularity of soft power initiatives and the expansion of Chinese political and economic engagement in their country. The third new discovery made in this analysis is related to the importance of the previous two discoveries. This discovery concerned the significance of China's use of scholarships in Tonga to its wider foreign relations strategy. This analysis found that Chinese scholarship provision is not unique to its relationship with Tonga, because it is adopting the same initiative in South Africa. This discovery is new because the popularity of Chinese scholarships among Tongan students has not been compared with China's other bilateral relationships. These three discoveries were made possible by the lack of previous research on the role of education in China's bilateral relationship with Tonga. This opened up a significant gap in the academic research which this paper has striven to fill.

The research undertaken in this paper has contributed to the existing academic field on China-South Pacific relations, and to the field of Chinese soft power provision. This is due to the relatively modern nature of soft power, as a theoretical framework it is a relatively recent phenomenon. This contribution is significant, because it shows that China is increasingly turning to soft power as part of its bilateral relationships with other countries, in tandem with traditional hard power initiatives. This is significant for several reasons. The first reason why it is significant is that it shows that China's use of scholarships in Tonga is connected to its wider foreign relations strategy, rather than a unique aspect of one relationship. This is significant because it shows that China values education as a key soft power tool in its foreign policy arsenal. As Nye highlighted when he established the theoretical framework of soft power, attraction is a key aspect of soft power, and the growing importance of education in China's foreign policy arsenal shows that it recognises this too. The second reason why this contribution is significant to the academic field is that it recognises the importance of soft power to China's global engagement. As Kurlantzick identified, China is increasingly turning to soft power as a means to reassure the rest of the world that it is not seeking to upset the traditional order with its rise. The findings of this paper contribute to this idea by highlighting the importance of soft power to an area that has not traditionally been a focus of Chinese 
foreign policy. This is significant, because it shows that China is adopting soft powerbased initiatives across its relationships, not just in those it considers strategically or economically vital. This is important, because it shows how important soft power is and the increasing importance of it to the debate on China's rise. The final reason why these findings are significant to the academic field on soft power is because it shows that the importance of soft power to the international relations debate is still growing. This is because soft power is becoming an increasingly significant part of the international relations debate, and the growing importance of it to state relations. This is significant to the international relations debate, because it signifies a possible change in focus of states from a hard power-focused foreign policy to one that emphasises and embraces fully the idea of soft power as the primary method for enhancing a states' power within the international system.

This thesis has made an important contribution to the academic study of soft power in the field of international relations. This contribution is the exposure of the link between education as a soft power tool and the expansion of political and economic engagement. The role that education plays in creating the conditions necessary for greater political and economic engagement have not been widely examined, especially in relation to China's relationship with the South Pacific. Education has been previously identified by scholars as a significant soft power tool in the arsenals of states. Despite this, there is only limited scholarship that analyses the relationship between this soft power tool and engagement. This thesis contributes to improving this scholarship by exposing a link between China's provision of scholarships in Tonga and the expansion of its political and economic engagement with the country. This link has also been reinforced by comparing it with China's relationship with South Africa. This finding highlights the importance of the thesis to the academic study of soft power.

This paper has analysed the role that education plays in China's quest for greater soft power in Tonga, and how it relates to its expanding political and economic engagement with the country. This research has challenged the conventional focus on hard power in China-South Pacific relations, and has identified previously unknown knowledge of Chinese policies in its relationship with Tonga. 
This has resulted in it making a significant and influential contribution to the academic debate on the role of soft power in Chinese foreign policy, how this relates to its wider aims, and the importance of soft power in general. 


\section{Chapter Six:}

\section{Recommendations}

The analysis undertaken in this paper has resulted in a number of recommendations that will guide future analysis of this topic. These recommendations focus on the scope of the analysis, the type of methodology used, and the limitations identified during this analysis.

The scope of the analysis undertaken in this paper was limited, due to a number of limitations experienced during the research process. Because of this, the analysis focused on a case study of a single state, and a comparison with a single state. This meant that the analysis was fairly limited in its findings and in the conclusions it reached. To better examine the field, future analysis of this subject area would be more effective if it were to widen the scope to include more South Pacific states in its analysis. This would allow the role of soft power in China's South Pacific relations to be better understood and highlighted, as it will provide a much more comprehensive examination of China's use of soft power. In addition to this, any future analysis should also consider broadening their comparison to include states in other parts of the world that have relations with China. This would make any future analysis more comprehensive, because it would enable China's use of soft power in the South Pacific to be assessed against its relations with countries that are not widely similar to those in the South Pacific. This would enable China's use of soft power to be assessed in a number of different environments.

The analysis undertaken in this paper was dictated in large part by the methodology, with the research method constraining the nature of the analysis. This affected the type of conclusion reached, as the analysis undertaken in this paper was constrained by the type of data that could be accessed. Any future analysis of this topic might consider a number of methodological changes from the approach adopted for this analysis. To better understand the effect that Chinese soft power is having in the South Pacific, an approach that measures opinions and attitudes among South Pacific peoples would be better placed. This could include the use of surveys, interviews, or other forms of quantitative research. This would be better able to add to the research in this paper, because it would measure the effectiveness of Chinese 
soft power, unlike this research which assessed China's soft power efforts. Adopting quantitative research methods for future analyses of this subject would complement the current research, adding a new dimension to the academic literature.

This research encountered several limitations, which constrained the scope and direction of the analysis. These limitations included issues around the sensitivity of the subject, issues around correspondence with foreign diplomats, and the nature of the subject area. The research focused on the issue of China-Tonga relations, which is considered somewhat of a sensitive subject by certain actors. This led to barriers being erected that prevented the author from obtaining information that would assist in the research. One such problem that arose from the issue of sensitivity was the unwillingness of the Chinese Embassy in Nuku'alofa to respond to requests for information on its scholarship programme. This made it difficult to obtain statistics regarding scholarship provision for the period that the embassy in Nuku'alofa was solely responsible for this programme. This made it difficult to obtain information for the research that was undertaken. These limitations were also evident in the attempts at correspondence with various South Pacific governments. As part of the research process, the author attempted to make contact with several South Pacific governments to obtain information and statistics regarding their relationships with China. During this process, the author failed to hear back from a number of governments, including those of Samoa, Fiji, Papua New Guinea and Vanuatu. This made it difficult to attempt a regional case study of Chinese soft power, which led to the decision to focus on the China-Tonga bilateral relationship. The third limitation that arose from the analysis was the lack of prior research in this particular subject area. This lack of prior research was a limitation, because it meant that there were no materials to use as a guide for framing the research. This provided a lot of freedom in how the analysis was conducted, but it also meant that the relevance of the analysis had to continually be ensured, so as not to stray off topic. These limitations influenced the way that the analysis and research was undertaken, but there are a number of recommendations that can minimise the effects of them.

To ensure effective data collection, correspondence should be started as early as possible with government departments and foreign embassies, to ensure as much time as possible to collect data. Where possible, contacting the person or department that is responsible for the subject your data is related can help in getting a prompt 
response. To adopt a qualitative research approach, it is suggested that travelling to the country that the research is focused on will ensure that survey collection can be undertaken. This is because a problem that arose during research was the need to be in the country to undertake survey distribution. The limitations identified in this section have affected the way that research was undertaken for this paper. This in turn affected the type of analysis that was undertaken, focusing on qualitative rather than quantitative analysis. To ensure that quantitative research is possible, the recommendations that were identified during the course of research for this paper can prevent similar issues from re-occurring. 


\section{Bibliography}

AFP, "Chinese Premier Wen to Visit the Pacific Islands", Taipei Times, April 32006

Apps, P., and Y. Torbati, "Asia Key as U.S., Eu Tighten Sanctions against Iran", Reuters, http://www.reuters.com/article/2012/02/13/us-iran-sanctions-asiaidUSTRE81C1C320120213.

AusAID, "Tonga", 2012,

http://www.ausaid.gov.au/countries/pacific/tonga/Pages/home.aspx (accessed November 1, 2012)

Australian Associated Press, "PNG Strengthens Ties with China", Courier Mail, June 30 2009

BBC, "China Support for Fiji Questioned", BBC, June 192009

BBC Monitor, "Solomons' Trade Balance with Australia Declines, China, Japan Increases", BBC, September 52006

Brady, Anne-Marie, "State Confucianism, Chineseness and Tradition in CCP Propaganda", in Anne-Marie Brady (ed.), China's Thought Management (London: Routledge, 2011)

Brady, Anne-Marie, and John Henderson, "New Zealand, the Pacific and China: Challenges Ahead." in Anne-Marie Brady (ed.), Looking North, Lookins South: China, Taiwan and the South Pacific (London: World Scientific, 2010)

Brown, T., Walters, A., Idione, N., Shaw, R., Wrighton, C., Bide, T., World Mineral Production 2006-2010 (Nottingham: British Geological Survey, 2012)

Bruce, S., and S. Yearley, The Sage Dictionary of Sociology (London: Sage Publications, 2006)

Central Intelligence Agency, "South Africa", 2012, https://www.cia.gov/library/publications/the-world-factbook/geos/sf.html (accessed December 7, 2012)

Central Intelligence Agency, "Tonga", 2012, https://www.cia.gov/library/publications/the-world-factbook/geos/tn.html (accessed November 1, 2012)

Chapman, Kate, "Chinese Loan Likely to Be Hard Going for Tonga", Stuff, July 142012 
China Daily, "Tonga Seeks $\$ 60 \mathrm{~m}$ Loan from China to Buy Back Assets", 2006, http://www.chinadaily.com.cn/bizchina/2006-04/27/content 585992.htm (accessed September 27, 2012)

China Scholarship Council. "China Government Scholarship Programme." http://www.csc.edu.cn/laihua/scholarshipdetailen.aspx?cid=97\&id=1422.

China Scholarship Council, "China Scholarship Council", 2012,

http://en.csc.edu.cn/About/c309df7fb3fa40b3a179a7ad93f11988.shtml

(accessed November 26, 2012)

China Scholarship Council, "China/PIF Scholarship Programme", 2012, http://en.csc.edu.cn/Laihua/scholarshipdetailen.aspx?cid=97\&id=1286 (accessed November 19, 2012)

Cho, Young Nam, and Ho Jong Jeong, "China's Soft Power: Discussions, Resources and Prospects," Asian Survey, vol. 48, no. 3, 2008

Confucius Institute Online, "Introduction to the Confucius Institutes", 2009, http://college.chinese.cn/en/article/2009-08/29/content 22308.htm (accessed November 21, 2012)

China Scholarship Council, "Statistics of the 2011 National Foreign Students", 2012, http://www.csc.edu.cn/Laihua/newsdetail.aspx?cid=47\&id=1256 (accessed November 29, 2012)

Craymer, Lucy "China Seeks to Star in South Pacific", 2012, http://online.wsj.com/article/SB1000142405270230381540457733452257 6045372.html (accessed September 25, 2012)

Crocombe, Ron, "The Software of China-Pacific Island Relations", in Anne-Marie Brady (ed.), Looking North, Looking South: China, Taiwan, and the South Pacific (London: World Scientific, 2010)

Davis, Lloyd Spencer, "Not All Tuna Are Created Equal", 2012, http://www.taimionline.com/articles/6654 (accessed September 28, 2012) Ding, Sheng, The Dragon's Hidden Wings: How China Is Rising with Its Soft Power (New York: Lexington Books, 2008)

Ding, Sheng, and Robert Saunders, "Talking up China: An Analysis of China's Rising Cultural Powerand Global Promotion of the Chinese Language", East Asia, vol. 23, no. 2, 2006 
Dobell, Graeme, "China and Taiwan in the South Pacific: Diplomatic Chess Versus Pacific Political Rugby", 2007,

http://lowyinstitute.cachefly.net/files/pubfiles/Dobell\%2C_China_and_Taiwa n_in_the_SP.pdf (accessed May 28, 2012)

Dominion Post, "Scholarships Take Students to China", Dominion Post, November 1 2012.

Barnett, Michael, and Raymond Duvall, "Power in Global Governance", in Michael Barnett and Raymond Duvall (ed.), Power in Global Governance (Cambridge: Cambridge University Press, 2005)

Embassy of the People's Republic of China in the Republic of South Africa, "EverDeepening China-South Africa Strategic Partnership", 2006, http://www.chinese-embassy.org.za/eng/zt/06wen/t257544.htm (accessed December 10, 2012)

Ministry of Foreign Affairs of the People's Republic of China, "Vice President Xi Jinping Meets with South Africa's President Zuma", 2012, http://www.fmprc.gov.cn/eng/zxxx/t954393.htm (accessed February 1, 2013)

Ferguson, Niall, Colossus: The Rise and Fall of the American Empire, (London: Penguin Books, 2004)

Fiji Times, "Bainimarama Backs Stand on Tibet", Fiji Times, March 292008

Fiji Times, "China Likes to Help Developing Nations", Fiji Times, November 102007

Finau, Ata'ata, Annual Foreign Trade Report for 2010 (Nuku'alofa: Statistics Department, 2010)

Finau, Ata'ata, Quarterly Foreign Trade Report (Nuku'alofa: Statistics Department, 2012)

Finau, Sitiveni, "Chinese Cultural Show Popular with Children," News Today, 28 May 2010

Garten, Jeffrey E, "China: The Missing Member at the G-8 Table", 2004, http://yaleglobal.yale.edu/content/china-missing-member-g-8-table (accessed November 21, 2012)

Grubel, James, "Pacific Micro-Nations Cash in on US-China Aid Rivalry", Reuters, September 42012

Gill, Bates, and Yanzhong Huang, "Sources and Limits of Chinese "Soft Power", Survival, vol. 48, no. 2, 2006) 
Goodman, D., "People's Republic of China", in R. Robison and D. Goodman (ed.), The New Rich in Asia (London: Routledge, 1996)

Gruenwald, Paul, Vincent Conti, Bora Bedamu Jr, Shu Zhen Pay, and Daniel Wilson, Pacific Quarterly (Sydney: ANZ, 2011)

Guttal, Shalmali, "Client and Competitor: China and the International Financial Institutions", in Dorothy-Grace Guerrero and Firoze Manji (ed.), China's New Role in Africa and the South (Oxford: Fahamu Books, 2008)

Hanson, Fergus, "China: Stumbling through the Pacific?", in Anne-Marie Brady (ed.), Looking North, Looking South: China, Taiwan and the South Pacific (Singapore: Word Scientific, 2010)

Hanson, Fergus, "Don't Ignore the Big New Player in Fiji", Sydney Morning Herald, May 92008

Hanson, Fergus, "The Dragon Looks South", 2008, http://lowyinstitute.cachefly.net/files/pubfiles/Hanson\%2C The dragon loo ks south Web.pdf (accessed May 28, 2012)

Hanson, Fergus, and Mary Fifita, "Behind China's Secret Aid Programme, Debt Looms", 2011, http://www.abc.net.au/unleashed/55376.html (accessed May 28, 2012) Hanson, Fergus, and Mary Fifita, "China in the Pacific: The New Banker in Town", 2011,

http://lowyinstitute.cachefly.net/files/pubfiles/Hanson and Fifita\%2C China in the Pacific web.pdf (accessed May 28, 2012)

Harris, Karen, "Waves of Migration: A Brief Outline of the History of Chinese in South Africa", in Martyn Davies (ed.), The China Monitor (Stellensbosch: Centre for Chinese Studies, 2007)

Henderson, John, "China, Taiwan and the Changing Strategic Significance of Oceania", Revue Juridique Polynesienne, vol. 1, no. 1, 2001

Herr, Richard, and Anthony Bergin, "U.S. Moves to Counter China in Pacific", The Australian, December 12011

Hoare, Stephen, "Inspiration from the East: Why Not Study in Asia?", The Independent, September 202012

Holyk, Gregory G, "Paper Tiger? Chinese Soft Power in East Asia", Political Science Quarterly, vol. 126, no. 2, 2011

Hook, Leslie, "Zuma Warns on Africa's Ties to China", Financial Times, July 192012 
Huang, Yanzhong, and Sheng Ding, "Dragon's Underbelly: An Analysis of China's Soft Power", East Asia, vol. 23, no. 4, 2006

Iati, Iati, "China and Samoa", in Terence Wesley-Smith and Edgar Porter (ed.), China in Oceania, (Oxford: Berghahn Books, 2010)

Jiao, Priscilla, "Culture a Key Priority in Five-Year Plan; Leaders Hope Industry Will Help Bolster Nation's 'Soft Power' Abroad; Cynics Fear Waste", South China Morning Post, March 282011

Jize, Qin, "Chinese Citizens Evacuated in Tonga", China Daily, November 232006

Keohane, Robert and Joseph S. Nye, Power and Interdependence, (Toronto: Little, Brown and Company, 1977)

Kuang, Heng Yee, "Power That Speaks Softly; from Panda Loans to Pop Culture, Countries Compete to Project Soft Power", The Straits Times, September 8 2012

Kurlantzick, Joshua, "China's Charm Offensive", Commentary, vol. 122, no. 3, 2006 Langa'oi, Palenitina, "China's Diplomatic Relations with the Kingdom of Tonga", in Terence Wesley-Smith and Edgar Porter (ed.), China in Oceania (Berghahn Books: Oxford, 2010)

Liang, Wei, "New Africa Policy: China's Quest for Oil and Influence", in Sujian Guo and Jean-Marc Blanchard (ed.), "Harmonious World" And China's New Foreign Policy (New York: Lexington Books, 2008)

Lin, Cheng-yi, "The Security Implications of Cross-Strait Competition in the South Pacific from a Taiwanese Perspective", in Anne-Marie Brady (ed.), Looking North, Looking South: China, Taiwan and the South Pacific (London: World Scientific, 2010.

Lintner, Bertil, "The Sinicizing of the South Pacific", Asia Times, April 182007

Lintner, Bertil, "The South Pacific: China's New Frontier", in Anne-Marie Brady (ed.), Looking North, Looking South: China, Taiwan and the South Pacific (London: World Scientific, 2010)

MacInnis, Laura, and Matt Spetalnick, "Obama Sends Military Advisors to Central Africa", Reuters, October 142011

MacMillan Dictionary, "Soft Loan - Definition", 2012, http://www.macmillandictionary.com/dictionary/british/soft-loan (accessed September 24, 2012) 
Matangi Tonga Online, "Woman Guilty of Trafficking and Enslaving Girls for

Prostitution", Matangi Tonga, April 262011

John J. Mearsheimer, “A Realist Reply”, International Security, vol. 20, no. 1, 1995

Mearsheimer, John, The Tragedy of Great Power Politics, (New York: W.W. Norton \&

Company, 2001)

MFAT, "Frequently Asked Questions About New Zealand's Policy Towards Fiji", 2010,

http://www.mfat.govt.nz/Foreign-Relations/Pacific/0-Fiji-FAQ.php (accessed

November 2, 2012)

Ministry of Foreign Affairs of the People's Republic of China, "Bilateral Relations",

2011, http://www.fmprc.gov.cn/eng/wjb/zzjg/fzs/gjlb/3094/ (accessed

December 7, 2012)

Ministry of Foreign Affairs of the People's Republic of China, "Vice President Xi

Jinping Meets with South Africa's President Zuma", 2012,

http://www.fmprc.gov.cn/eng/zxxx/t954393.htm (accessed December 7, 2012)

Ministry of Information and Communications, "Queen Nanasipau'u Honored

Handover Ceremony of Nuku'alofa CBD Phase 1 Reconstruction Project", 2012,

http://www.pmo.gov.to/news-today/royalty/3987-queen-nanasipauu-

honored-handover-ceremony-of-nukualofa-cbd-phase-1-reconstruction-

project (accessed October 21, 2012)

Nadkarni, Dev, "Logged to Death", NZ Herald, July 142007

Nelson, Hank, "Chinese in Papua New Guinea", in Terence Wesley-Smith and Edgar

Porter (ed.), China in Oceania (Oxford: Berghahn Books, 2010)

New Zealand Aid Programmeme, "Aid Allocations 2011/12", 2011,

http://www.aid.govt.nz/about-aid-programmeme/aid-statistics/aid-

allocations-20112012 (acessed November 1, 2012)

New Zealand Aid Programmeme, "New Zealand and China Collaborate on World First in Development", 2012, http://www.aid.govt.nz/media-and-

publications/development-stories/september-2012/new-zealand-and-china-

collaborate-world-fi (accessed January 17, 2013)

New Zealand Government, "PM: Nuclear Security Summit an Important Step Forward", 2012, Scoop, March 272012 
Ntshinga, Madoda, (Deputy High Commissioner, South African High Commision,

Wellington), email communication to the author, December 3, 2012

Nye, Jr., Joseph S., "Soft Power and Higher Education", 2004,

http://net.educause.edu/ir/library/pdf/ffpiu043.pdf (accessed May 26, 2012)

Nye, Jr., Joseph S., Bound to Lead: The Changing Nature of American Power (New York: Basic Books, 1990)

Nye, Jr., Joseph S., The Future of Power (New York: Public Affairs, 2011)

Nye, Jr., Joseph S., Soft Power: The Means to Success in World Politics (New York:

Public Affairs, 2004)

Pacific Islands Forum, "China-PIFs Scholarships 2010/2011 Intake", 2010,

http://www.forumsec.org/pages.cfm/newsroom/press-

statements/2010/china-pifs-scholarships-2010-2011-intake.html (accessed

November 7, 2012)

Radio NZ, "Tonga Fisheries Imposes Three Year Ban on Sea Cucumbers", Radio New Zealand, May 26, 2012

Ramos, Joshua Cooper, The Beijing Consensus (London: Basic Books, 2004)

Real, Natalia, "Chinese Subsidies Are Damaging the Pacific Islands Tuna Sector", 2012,

http://fis.com/fis/worldnews/worldnews.asp?monthyear=\&day=17\&id=546

$\underline{86 \& \mathrm{l}=\mathrm{e} \& \mathrm{special}=0 \& \mathrm{ndb}=0}$ (accessed September 28, 2012)

Reuters, "China Becomes S.Africa's Top Export Destination", Reuters, October 22009

Ride, Anouk, "FFA Members Support Tonga's Bid to List Vessel for Illegal Fishing",

2012, http://www.ffa.int/node/68 (accessed October 20, 2012)

RNZ International, "China Calls for More Understanding from Fiji's Neighbours", Radio New Zealand, November 292007

Saunders, Philip C, "Chinese Foreign Policy in Asia: Implications for the South Pacific", in Anne-Marie Brady (ed.), Looking North, Looking South: China, Taiwan and the South Pacific (London: World Scientific, 2010)

Sautman, Barry, and Yan Hairong, "Friends and Interests: China's Distinctive Links with Africa." in Dorothy-Grace Guerrero and Firoze Manji (ed.), China's New Role in Africa and the South (Oxford: Fahamu Books, 2008)

Schloss, Glenn, "Passport Trade Worth Billions", South China Morning Post, 1996 
Schuetze, Christopher F. "Asian Universities Jump in Rank; While Recruiters Still Put the U.S. And Europe on Top, China Is Moving Up", The International Herald Tribune, October 252012

Scott, J., and G. Marshall, Oxford Dictionary of Sociology, (New York: Oxford University Press, 2005)

Scruton, R., A Dictionary of Political Thought (London: MacMillan Press, 1982)

Shie, Tamara-Renee, "Rising Chinese Influence in the South Pacific: Beijing's Island Fever", in Anne-Marie Brady (ed.), Looking North, Looking South: China, Taiwan and the South Pacific (London: World Scientific, 2010)

Singh, Shivani, "Papua New Guinea's Ramu Nickel Project 'Operating as Normal'", Metal Bulletin, April 122012

Skehan, Craig, "Pawns in a Diplomatic Poker Game", Sydney Morning Herald, December 182004

Telefoni, Pelenaise (Tongan diplomat, Scholarships Unit), email message to the author, October 18, 2012

Teo, F, "China-Pacific Islands Forum Scholarship, 2010/2011 Intake", 2010, http://www.forumsec.org/resources/uploads/attachments/documents/Circ \%2024\%20China\%20PIF\%20Scholarship\%202010\%202011\%20Intake.pdf (accessed October 20, 2012)

To, James Jiann Hua, "Sino-Pacifica: Extra-Territorial Influence and the Overseas Chinese", in Anne-Marie Brady (ed.), Looking North, Looking South: China, Taiwan and the South Pacific (London: World Scientific, 2010)

Tonga Chamber of Commerce and Industry, "Facts About Tonga", 2010, http://www.tongachamber.org/tonga-factsheet (accessed October 19, 2012) Tonga Department of Statistics, "Air Visitors", 2012, http://www.spc.int/prism/tonga/index.php/tourism-statistics/81-airvisitors (accessed October 19, 2012)

Tonga Department of Statistics, "GDP Bulletin" (Nuku'alofa: Statistics Department, 2012)

Tonga Department of Statistics, "Tonga 2006 Census of Population and Housing, Volume 2: Analytical Report", (Nuku'alofa: Statistics Department, 2008) 
Tonga Department of Statistics, "International Trade Summary", 2012, http://www.spc.int/prism/tonga/index.php/economic/merchandise-trade (accessed November 1, 2012)

Tu'ivakano, Siale'ataonga, "Growing Our Economy: A Collective Effort", (speech, Nuku'alofa, March 7 2012), Ministry of Information and Communications, http://www.pmo.gov.to/news-today/press-releases/3440-prime-ministerlord-tuivakano-opening-address-at-the-economic-dialogue-2012-qgrowingour-economy-a-collective-effortq

Wang, Yiwei, "Public Diplomacy and the Rise of Chinese Soft Power", The Annals of the American Academy of Political and Social Science, vol. 616, no. 1, 2008

Weizhong, Xu, "Sino-African Relations", in Dorothy-Grace Guerrero and Firoze Manji (ed.), China's New Role in Africa and the Global South (Bangkok: Fahamu, 2008)

Wendt, Alexander, "The Agent-Structure Problem in International Relations Theory", International Organization, vol. 41, no. 3, 1987

Wendt, Alexander, Social Theory of International Politics (Cambridge: Cambridge University Press, 1999)

Wesley-Smith, Terence, "China's Pacific Engagement", in Terence Wesley-Smith and Edgar Porter (ed.), China in Oceania (New York: Berghahn Books, 2010) Wesley-Smith, Terence, and Edgar Porter, "Oceania Matters", in Terence WesleySmith and Edgar Porter (ed.), China in Oceania (New York: Berghahn Books, 2010)

Windybank, Susan, "The China Syndrome", Policy, vol. 21, no. 2, 2005

Xuequan, Mu, "China, Papua New Guinea Vow to Expand Military Cooperation", Xinhua, June 262009

Yang, Jian, "The South Pacific in China's Grand Strategy", in Anne-Marie Brady (ed.), Looking North, Looking South: China, Taiwan and the South Pacific (London: World Scientific, 2010)

Young, Audrey, "China's Aid to the Pacific Tops \$800m", NZ Herald, April 112011 Young Nam, Cho, and Jeong Jong Ho, "China's Soft Power: Discussions, Resources and Prospects", Asian Survey, vol. 48, no. 3, 2008

Ziring, L., J. Plano, and R. Olton, International Relations: A Political Dictionary (Santa Barbara: ABC-CLIO, 1995) 
